\title{
Microcantilever investigation of fracture toughness and subcritical crack growth on the scale of the microstructure in $\mathrm{Al}_{2} \mathrm{O}_{3}$
}

\section{A. D. Norton, S.Falco, N. Young, J. Severs, R.I. Todd*}

University of Oxford, Department of Materials

Parks Road, Oxford OX1 3PH, UK.

*Corresponding author: richard.todd@materials.ox.ac.uk

Keywords: micromechanical testing; toughness; subcritical crack growth; alumina; focused ion beams

\begin{abstract}
Knowledge of the fracture characteristics of individual microstructural features such as grains and grain boundaries is essential for a full understanding of the macroscopic behaviour of ceramics. We have investigated the fracture of single crystal, bicrystal and polycrystalline $\mathrm{Al}_{2} \mathrm{O}_{3}$ on the micrometre scale by testing microcantilevers containing notches and artificial flaws introduced at features of interest (e.g. grain boundaries) using focused ion beams (FIB). The specimens were loaded to fracture using a nanoindenter and tests were performed under air, water and silicone oil. The results were influenced significantly by ion implantation at the notch tip, moisture assisted slow crack growth and finite notch tip radius. Methods of avoiding these effects or correcting for them are proposed. It is shown that using these methods, the fracture toughness $\left(K_{c}\right)$ and threshold stress intensity for subcritical crack growth $\left(K_{0}\right)$ can be measured in individual grains and grain boundaries of typical microstructures.
\end{abstract}

\section{Introduction}

Ceramics are the most brittle of materials and this causes them to exhibit unpredictable strength and catastrophic failure. They are used despite these problems because of their high hardness, chemical inertness and high temperature capability as well as a host of unique functional properties. The 
characterisation and understanding of their fracture is therefore of great importance and there is a long history of fruitful investigations of the fracture behaviour of ceramics using macroscopic test specimens $[1,2]$

There has been less use of specimens on the scale of the microstructure for the investigation of the fracture properties of ceramics. Such microscopic specimens have the potential to provide a range of complementary information. They could, in principle, be used to measure directly the resistance to fracture of individual microstructural features such as grains or grain boundaries which cannot be measured in isolation in macroscopic specimens but which nevertheless determine the global fracture response. Microscopic specimens could also be used to investigate the subcritical growth of cracks at very slow rates, which is essential information in designing for long term reliability but which is difficult to measure on a laboratory timescale using macroscopic specimens because of the very slow crack tip velocities involved. In ceramics containing $R$ curves, the short crack behaviour which determines the strength of real components and the fundamentals of crack initiation could also be investigated.

Brittle fracture happens most readily in response to tensile stresses. Various forms of bend test are common for producing tensile stress states in both macroscopic and microscopic specimens. Ceramic microcantilevers were first made and tested in bending using a nanoindenter as long ago as 1988, in silicon [3] and in thin films of Au and $\mathrm{SiO} 2$ deposited on silicon [4]. The specimens in both cases were unnotched and were made using lithographic techniques drawn from the electronics industry. These fabrication techniques are not suitable for most ceramics, however, so more general methods are needed for the production of test specimens. Toughness measurements on silicon and CVD WC films were made by focused ion beam (FIB) milling notched microcantilevers by Di Maio and Roberts in 2005 [5]. This method is applicable to a much wider range of materials. The toughness measured in the silicon, used as a reference material, gave reasonable values but were $15-30 \%$ higher than literature 
values from macroscopic specimens. This was attributed to the fact that the FlBed notches were not perfectly sharp.

Further experiments on single crystal silicon have been reported recently by Jaya et al. [6] who compared four different microscale test geometries, all produced by FIB milling. The results from all four methods agreed both with one another and with the accepted macroscopic values for fracture on the relevant crystallographic plane. Some of the techniques used involved stable crack growth so that a "natural" sharp crack, free from ion implantation damage at the crack tip was being tested. Failure directly from FIBed notches in microcantilever specimens, which are potentially susceptible to both blunt notch tips and ion implantation damage, gave the same toughness values however, leading the authors to conclude that notches with root radii of less than $200 \mu \mathrm{m}$ give valid results and that ion implantation had a negligible effect on measurements in silicon.

Very recently, Tatami et al. [7] have used similar procedures to measure the fracture toughness of grains and grain boundaries in liquid phase sintered $\mathrm{Si}_{3} \mathrm{~N}_{4}$. The elongated $\beta$ - $\mathrm{Si}_{3} \mathrm{~N}_{4}$ grains in such microstructures enabled straight notches to be machined across a single grain or grain boundary spanning the beam width. The effect of different rare-earth dopants on grain boundary toughness could be distinguished and was in accord with expectations from crack deflection measurements at grain boundaries in these materials. The grain toughness was greater than that of the grain boundaries, qualitatively in accord with expectation from the intergranular fracture mode in these materials.

The results on non-oxide ceramics discussed above suggest that such techniques could be usefully applied to a wide range of brittle materials such as oxide ceramics. Toughness measurements on nanograined alumina fibres and amorphous fused quartz have recently been reported by Mueller et al. [8]. The measurements were made using chevron notches in microcantilevers. This notch geometry allows stable crack growth before final failure, thus avoiding the influence of notch tip radius and ion 
implantation. This geometry is thus attractive for testing microstructures which are constant through the thickness of the microcantilever specimen such as the nanograined and amorphous materials investigated. This requirement is specified because the chevron notch geometry involves deep notching over most of the cross section of the specimen, which has typical dimensions $\sim 2 \mu \mathrm{m}$. As most engineering ceramics have mean grain sizes on the scale of $0.5-5 \mu \mathrm{m}$, however, it is difficult to fabricate a specimen in which the final fracture, after some stable crack growth occurs on a feature of interest such as a grain boundary and on that feature alone. Additional testing methods are therefore needed.

In view of the apparent success of simply notched microcantilevers in silicon above, the present paper investigates the possibility of using short notches and artificial flaws machined into microstructural features of interest on the tensile surface of microcantilevers to provide valid toughness measurements in alumina-based materials, which are the most widely used structural ceramics. The effects of notch tip radius, ion implantation at the notch tip and environment are first investigated using single crystals and bicrystals. Finally, direct threshold toughness measurements of individual grain boundaries in polycrystalline alumina are reported for the first time.

\section{Experimental}

\subsection{Materials}

2.1.1 Single and bi-crystal sapphire. Single crystal sapphire was from two sources. The microcantilever beams on $m-, c_{-}$, and $a$-plane sapphire were from Shinkosha, Japan. $c$-plane sapphire used for the diffusion bonded specimen was from Fluoroware Inc. Both were polished by the supplier.

In order to produce a flat grain boundary of known character, two pieces of c-plane sapphire were ultrasonically cleaned in acetone for 2 hours and annealed in air at $1200^{\circ} \mathrm{C}$. The pieces were diffusion bonded together with a twist angle of $\approx 20^{\circ}$ by hot-pressing $\left(1550^{\circ} \mathrm{C}, 30 \mathrm{~min}, 20 \mathrm{MPa}\right.$, argon). The quality 
of the bonding was confirmed using Transmission Electron Microscopy of a FIBed foil milled across the boundary (FEI FIB200) (Section 3.1). The boundary was difficult to detect in optical or electron microscopes; hence, after polishing to a finish of $1 \mu \mathrm{m}$, the sample was thermally etched $\left(1400^{\circ} \mathrm{C}, 10\right.$ $\min )$.

2.1.2 Polycrystalline alumina. TM-DAR alumina powder (>99.99\% purity, mean particle size $150 \mathrm{~nm}$, Taimei Chemicals Co., Ltd, Tokyo, Japan) was used. Slurries with the following composition were ball milled in a polyethylene bottle ( 24 hours): $100 \mathrm{~g}$ powder, $400 \mathrm{~g}$ alumina milling balls, $350 \mathrm{ml}$ ethanol, $0.25 \mathrm{wt} \% \mathrm{MgO}$ (UBE, Japan, 120nm mean particle size). Slurries were dried in a rotary evaporator (IKA RV10, Jencons, Germany). In order to break down agglomerates, dry ball milling was performed for 24 hours. Powders were passed through a $150 \mu \mathrm{m}$ sieve and calcined $\left(600^{\circ} \mathrm{C}, 1 \mathrm{~h}\right)$ to remove any organic material and were then uniaxially pressed (50 MPa, 5 minutes, $32 \mathrm{~mm}$ diameter die), cold isostatically pressed (200 MPa), and sintered in vacuum under a graphite powder bed (Lenton Furnaces, $1500{ }^{\circ} \mathrm{C}, 1$ hour, $10^{\circ} \mathrm{C} / \mathrm{min}$ heating and cooling rate). After sintering, discs were flat-bed ground to remove approximately $0.75 \mathrm{~mm}$ of material from each face and cut into smaller pieces. The faces were polished to a $1 \mu \mathrm{m}$ finish. The results shown here come from the central region of the disc. The density was measured using the Archimedes technique.

\subsection{Microstructure and composition}

2.2.1 TEM-EDX. TEM samples of the single and bi-crystal specimens were produced using Focused lon Beam milling (FEI FIB200). A $2 \mu \mathrm{m}$ layer of platinum was deposited to protect the top surface during the sample preparation. The samples were thinned to $60-80 \mathrm{~nm}$ using beam currents of $500-1000 \mathrm{pA}$ in the final stages and then lifted out ex situ onto an amorphous carbon film supported on a copper grid.

Polycrystalline TEM specimens were prepared by conventional mechanical thinning of $3 \mathrm{~mm}$ discs followed by dimpling and ion beam thinning to perforation. 
The samples were examined using a JEOL 2000FX TEM (200kV, LaB6 source) and a JEOL 3000F TEM (300

kV, LaB 6 source). EDX spectra were analysed using INCA software with a Cliff-Lorimer thin ratio quantification method [9].

The misorientation across the diffusion bonded grain boundary was determined by transmission electron diffraction (JEOL JEM-2000FX) as well as by EBSD (section 2.2.2).

The structure of the ion implanted surface layer was examined at high resolution using nanobeam diffraction (JEOL 2010, $200 \mathrm{kV}$ ) with a probe size $\approx 5 \mathrm{~nm}$.

2.2.2 SEM-EBSD. The microstructure of the polycrystalline alumina was examined using SEM (JEOL JSM$840 F$ and JEOL JSM-6500F) of diamond polished specimens thermally etched at $1550^{\circ} \mathrm{C}$ for 30 minutes. The mean grain size was determined as 1.57 [10] times the mean linear intercept (ASTM Standard E 11288). The misorientation across the diffusion bonded grain boundary was determined by EBSD (JEOL JSM6300, EDAX-TSL EBSD system, 20kV).

\subsection{Micromechanical testing}

2.3.1 Production of microcantilevers. Microcantilever beams were milled from flat surfaces using FIB (FEI FIB200, 30kV). A uniform triangular cross-section was chosen because it is the easiest to make in the presence of beam drift from specimen charging, which is almost inevitable in a non-conducting ceramic such as alumina. To minimise the extent of beam drift, a $10 \mathrm{~nm}$ layer of platinum was deposited on the surface prior to milling (Cressington 208HR high resolution sputter coater); this was occasionally reapplied if removed by the FIB during milling.

To produce a beam, a U-shaped trench was milled (7000 pA beam current) to a depth of about $8 \mu \mathrm{m}$. The beam was then formed by first tilting to $45^{\circ}$ and undercutting to a depth of $\sim 10 \mu \mathrm{m}$ using a current of $5000 \mathrm{pA}$, and then rotating by $180^{\circ}$ and repeating the process to form the basic cantilever. The 
undercut faces and the free end of the beam were then cleaned of redeposited material using a lower beam current (1000 pA). Beam dimensions were measured in the SEM (JEOL JSM-6500F). The microcantilever beam was titled to $50^{\circ}$ in the SEM to measure the height (using the appropriate factor to compensate for the foreshortening of the inclined surface). Typical dimensions were: length $25 \mu \mathrm{m}$, width $4 \mu \mathrm{m}$, height $2.4 \mu \mathrm{m}$. The corresponding angle at the apex was always close to $80^{\circ}$ rather than the $90^{\circ}$ expected from the milling geometry. This is thought to be because of the cone of the focused beam and because of its deflection away from the specimen by charging. An example of a beam in the bicrystal at this stage is shown in Fig. 1.

Straight through notches or rectangular flaws were FIBed normal to the top surface of the beams and to the length of the beam. Most were milled to a depth of about $0.3 \mu \mathrm{m}$ at $10 \mathrm{pA}$. The notch or flaw dimensions were measured more accurately from the fracture surfaces after testing. In order to investigate the influence of tip radius, several beams were also notched with higher beam currents of 100 and $1000 \mathrm{pA}$.

Some beams were annealed in vacuum before testing to investigate the effect on the implanted layer and associated residual stresses at the notch tip. Beams on the surface of diffusion bonded sapphire were notched at the boundary or in the sapphire matrix, before annealing in vacuum at $1000^{\circ} \mathrm{C}$ for $1 \mathrm{~h}$. Several microcantilevers were broken, and the sample re-annealed at $1100^{\circ} \mathrm{C}$. Several more microcantilevers were broken and the sample re-annealed to $1200^{\circ} \mathrm{C}$. Finally the remaining microcantilevers were broken.

Owing to the fine grain size of the TM-DAR, it was difficult to find boundaries which were sufficiently long to mill straight through notches. Only one such beam was tested; the majority of beams had flaws FIBed into boundaries whose surface trace was normal to the loading direction. 
2.3.2 Mechanical testing of microcantilevers. The basic testing method was as described by Armstrong et al. [11]. A MTS Nanoindenter XP with a Berkovich tip and NanoVision stage was used to test the microcantilevers. The position of each microcantilever was established by using the AFM scanning mode of the NanoVision stage. The beam was then loaded at a point on the centre line near the free end with a displacement rate of $5 \mathrm{~nm} / \mathrm{s}$ until failure. The relative humidity of the atmosphere in the testing area was $52 \pm 8 \%$ (Omegaette HH311, Omega).

Similar tests were also performed with the beam submerged in water or silicone oil by placing several drops of liquid on the surface of the sample prior to engaging the nanoindenter. The liquid covered the tip throughout the testing procedure.

For straight through notches, the stress intensity $K$ was determined using finite element compliance analysis to be:

$K=\frac{12 F L_{n}}{w h^{2}} \cdot 1.12 \sqrt{\pi \alpha}\left(1+0.123 \alpha^{\prime}+5.456 \alpha^{\prime 2}+0.073 \alpha^{\prime 3}-0.023 \alpha^{\prime 4}\right)$

Where $F$ is the force applied by the nanoindenter, $L_{n}$ is the distance from the load point to the notch, $w$ and $h$ are the microcantilever cross sectional width and height, $\alpha$ is the notch depth and $\alpha^{\prime}$ is $\alpha / h$. This equation is valid for $\alpha^{\prime}<0.4$ and reduces to the value for a short edge crack under the stress predicted by the Euler-Bernoulli beam theory for small values of $\alpha^{\prime}$. Details of the derivation are given in the Appendix.

Stress intensity factors for our artificial, FIB milled flaws were estimated using the equations of Strobl et al. [12] for this geometry. Strobl et al. give equations for the dimensionless factor $M$, depending on the dimensions of the flaw and the beam and on Poisson's ratio, in the equation:

$$
K=M \sigma_{n} \sqrt{\pi \alpha}
$$


for partial elliptical flaws in rectangular beams, where $\sigma_{n}$ is the surface tensile stress at the flaw position. We approximate our rectangular flaws to semi-elliptical flaws of the same depth and width, breaking the surface along the major axis and using the width of the triangular beam in place of the rectangular beam width. In addition to obeying the limits of validity of the equations specified by Strobl et al., we imposed the following additional conditions to mitigate the differences between the geometry assumed in the equations for $M$ and that of our experiments:

1. In recognition that the neutral axis of the triangular beam is $h / 3$ beneath the tensile surface in the triangular beam, we use an effective height of $2 h / 3$ in the Strobl equations.

2. To reduce the effect of the sloping side faces of the triangular beam, we only used flaws whose closest distant to any edge or corner of the cross section was greater than the flaw half-width.

3. To ensure that the maximum stress intensity factor was at the base of the notch (and not at the sides), a depth to half-width ratio $<0.6$ was used.

2.3.3 Bulk nanoindentation. The effect of implantation on the hardness of c-plane sapphire was investigated by making 25 nanoindentations to a depth of $100 \mathrm{~nm}$ on implanted and unimplanted surfaces using a Berkovich indenter with silica calibration (Nanoindenter XP, MTS). The implanted specimen was produced by imaging the surface 15 times with the ion beam (1000pA beam). Very short $(<0.1 \mathrm{~s})$ exposure times were used to reproduce the type of damage expected to occur on the top surface of a microcantilever.

2.3.4 Implantation stress from curvature measurement. In order to estimate the residual stresses caused by Ga-ion implantation during FIBing, a TEM liftout sample was produced as above from a surface of single crystal ruby which had previously been imaged in the FIB, and thereby implanted with Ga-ions (Fig. 2). Assuming no other sources of stress variation, the in-plane curvature of the sample 
caused by the implanted layer at one side can be used to calculate the residual stress using the plane stress version of the Stoney equation [13]:

$\sigma_{R}=\frac{E d^{2}}{6 t} \cdot \frac{1}{r}$

where $\sigma_{R}$ is the stress in the implanted region, $E$ is Young's modulus of the ruby, $d$ is the width of the lift out specimen normal to the implanted edge, $t$ is the thickness of the implanted region and $1 / r$ is the curvature. The curvature was measured indirectly by using the resulting stress gradient $\mathrm{d} \sigma_{s} / \mathrm{d} y$ in the specimen, where $\sigma_{s}$ is the stress in the lift out specimen away from the implanted layer and $y$ is the distance along a path in the plane of the specimen and normal to the implanted edge. $\sigma_{s}$ was measured as a function of $y$ using $\mathrm{Cr}^{3+}$ optical fluorescence microscopy line scans. Ruby was used to increase the intensity of the $R$ peaks of the fluorescent spectrum, which are produced by electronic transitions associated with substitutional $\mathrm{Cr}^{3+}$ impurities in the $\mathrm{Al}_{2} \mathrm{O}_{3}$ lattice. The relationship between the frequency shift $\Delta v$ of the $R_{1}$ or $R_{2}$ peak from its stress free position and the uniaxial stress is given by:

$\Delta v=\Pi \sigma_{s}$

where $\Pi$ is the piezospectrosopic coefficient for the relevant peak in the crystallographic direction in which the stress is applied. Using the crystallographic orientation of the specimen and the piezospectroscopic coefficients of $\mathrm{He}$ and Clarke [13] gave a value for the $R_{1}$ peak of $\Pi=2.9 \mathrm{~cm}^{-1} \mathrm{GPa}^{-1}$. The curvature can then be calculated as:

$\frac{1}{r}=\frac{1}{E} \cdot \frac{\mathrm{d} \sigma_{s}}{\mathrm{~d} y}=\frac{1}{\Pi E} \cdot \frac{\mathrm{d} v}{\mathrm{~d} y}$ 
$\frac{\mathrm{d} v}{\mathrm{~d} y}$ was measured from line scans made using a confocal Raman microscope (System 1000, Renishaw, UK, $633 \mathrm{~nm}$ He-Ne laser, probe size $\sim 2 \mu \mathrm{m}$ ) equipped with a mapping stage. Note that this technique relies on stress measurements made in undamaged material, away from the implanted layer.

\section{Results}

\subsection{Microstructures and compositions}

Figure 3 shows a TEM micrograph of the diffusion bonded grain boundary where it meets the surface of the bicrystal. Although regions could be found (not shown) where bonding was incomplete, most of the boundary was well bonded and without interfacial cavities. The boundary was flat and free of a substantial glassy film. EDX showed the presence of Ca (nominally $2 \pm 1$ at\%) and Si (4 \pm 2 at\%) impurities at the boundary, along with a small amount of $\mathrm{Ga}(0.3 \pm 0.1$ at\%) from the FIB preparation. Only Ga was detected away from the boundary. EBSD showed that the twist angle of the grain boundary was $19.7 \pm 0.9^{\circ}$ and this was confirmed by electron diffraction in the TEM.

The polycrystalline alumina had a relative density of $99.997 \pm 0.002 \%$. The mean grain size was $2.2 \pm 0.2$ $\mu \mathrm{m}$.

\subsection{Nature of the notch and implanted layer}

Cross sectional TEM micrographs of notches milled in sapphire microcantilevers using three different beam currents are shown in Fig. 4. For currents of 10,100 and 1000 pA, the notches had root radii of $14.5 \pm 0.1,31.6 \pm 0.5$ and $75.9 \pm 1.9 \mathrm{~nm}$ respectively. Under the light-coloured layer of redeposited material produced during notching there is a dark surface layer within the sapphire itself. The Ga content in this surface layer was measured using EDX to be $3 \pm 1$ at $\%$, much greater than the 0.3 at $\%$ 
found away from the surface, demonstrating that this layer is caused by Ga ion implantation during the original FIB imaging of the surface and milling of the notch. Since the FWHM of the EDX probe size (72 $\mathrm{nm}$ ) was larger than the implanted layer thickness, this probably represents an underestimate of the Ga content. The depth of implantation was the same on the surface as at the root of the notch and was $20.5 \pm 1.2 \mathrm{~nm}$ independent of beam current, because the depth is primarily determined by the acceleration voltage of $30 \mathrm{kV}$.

HRTEM and nanobeam diffraction showed that the implanted layer was crystalline with the same lattice as the underlying unimplanted material (Fig. 5). The amorphous halo in Fig. 5b is from the carbon support film and the small number of extra diffraction spots are presumed to be from the redeposited material. There was a slight increase of up to $2 \mathrm{GPa}$ in the hardness due to the gallium implantation (Fig. 6) for indentation depths $<20 \mathrm{~nm}$, which was close to the measured implantation thickness. This is attributable to lattice defects introduced by ion implantation [15-17].

Figure 7 shows a TEM cross section of an annealed notch. Annealing did not change the profile of the notch for a given beam current and at $4 \pm 1$ at $\%$ the nominal Ga content in the implanted layer was unchanged by the annealing treatment. This is not surprising: the $\mathrm{Al}_{2} \mathrm{O}_{3}-\mathrm{Ga}_{2} \mathrm{O}_{3}$ phase diagram [18] shows extensive solid solubility of $\mathrm{Ga}_{2} \mathrm{O}_{3}$ in $\alpha-\mathrm{Al}_{2} \mathrm{O}_{3}$ at the annealing temperatures and the ionic radius of $\mathrm{Ga}^{3+}$ is $17 \%$ bigger than that of $\mathrm{Al}^{3+}$ so diffusion is expected to be slow. $\mathrm{Ga}_{2} \mathrm{O}_{3}$ shows little volatility at temperatures below $1200^{\circ} \mathrm{C}[19]$.

\subsection{Implantation residual stress}

Figure 8 shows the variation in $R 1$ fluorescence peak position as a function of distance $y$ along a line normal to the ion implanted edge of the FIB lift out specimen. The specimen was $5.0 \pm 5 \mu \mathrm{m}$ in width ( $d$ in eq. 3 ) and most of the points in the $3 \mu \mathrm{m}$ of the line scan furthest from the implanted layer lie along a 
well defined straight line. Assuming the specimen remains planar and the implanted layer is the only source of stress, a compressive residual stress $\sigma_{R}=-16 \pm 6 \mathrm{GPa}$ was estimated using eq. 4 from several scans such as that in Fig. 8. The departure from linearity within $1.5 \mu \mathrm{m}$ of the implanted side could be caused by buckling of the specimen or by slightly more implantation at this side during FIBing of the lift out specimen. An increase in peak width in the same region supports the latter explanation and this is reasonable given the geometry of the milling process. The stress value is therefore likely to be an overestimate although the low Ga concentration away from the implanted edge and the relatively small perturbation of the line in Fig. 8, which corresponds to stresses $\sim 100 \mathrm{MPa}$, suggest that the implantation stresses are the dominant effect. Similarly, the layer of platinum deposited before milling of the specimen from the surface (section 2.2.1) may also contribute to the curvature but as we do not know of any measurements of residual stress in FIB-deposited platinum, it has been necessary to ignore it in the present calculations.

Such a high value of residual stress is plausible. Burnett \& Page [20] implanted the surface of polished sapphire with titanium and yttrium ions at $300 \mathrm{keV}$, to a depth of $0.5 \mu \mathrm{m}$. This resulted in a residual stress, due to both the formation of vacancy / interstitial pairs and the injection of atoms into the surface, of a maximum of 6.4 and 7.6 GPa for titanium and yttrium doping respectively. The fluences (ions $/ \mathrm{cm}^{2}$ ) used in these experiments are of the same order as those that could be expected to be achieved using gallium Focused Ion Beams $\left(10^{17}-10^{18} \mathrm{~cm}^{-2}\right)[21,22]$. Although the ions implanted in the FIB have lower incident energies ( $30 \mathrm{keV})$, they are confined to a much narrower surface layer so it is reasonable to expect very high stresses to develop in the implanted region. Nanobeam diffraction from the implanted layer suggested linear lattice expansions of several \% compared with unimplanted sapphire. This is commensurate with the stresses measured and is much bigger than can be explained in terms of the greater ionic radius of $\mathrm{Ga}^{3+}$ in solid solution with the concentrations measured. This suggests that the source of the compressive stresses is lattice expansion due to interstitial implantation. 


\subsection{Microcantilever results: fractography}

Figure 9 shows fracture surfaces from the different types of specimen investigated. Fracture surfaces for notches orientated for fracture on the $m$ - and $a$-planes in single crystals were smooth and flat in the upper part of the beam where fracture initiated (Fig. 9a). The crack path sometimes deviated from the straight-through path in the lower part of the beam, as is shown in Fig. 9b for a blunt notch milled with a beam current of $1000 \mathrm{pA}$. This effect, occurring in the initially compressive portion of the beam, is known as cantilever curl and is well known from macroscopic specimens $[23,24]$. The blunt notches also led to hackle marks (Fig. 9b) on the fracture surface, indicating a rapid acceleration of the crack tip after fracture initiation in these cases. Figure $9 c$ shows the fracture surface of a specimen containing a FIBed flaw on the a-plane. Again, the surface is flat and smooth in the vicinity of the flaw. The hackle pattern evident further away confirms that fracture initiated at the artificial flaw.

In contrast, specimens orientated for fracture on the c-plane showed heavily facetted fracture surfaces (Fig. 9 d). This is again consistent with the findings of macroscopic studies which have shown that the basal plane has an extremely high toughness $[25,26]$. The orientations of many of the facets in Fig. $9 d$ appear consistent with them being on the $r$-plane, which has a much lower toughness [26].

The fracture surface resulting from a notch on the diffusion bonded grain boundary was smooth and flat (Fig. 9e), indicating that the crack had nucleated at the intersection of the boundary and the notch and propagated along the boundary.

Figure $9 \mathrm{f}$ shows the fracture surface of a polycrystalline alumina specimen which has failed from a FlBed flaw. The fracture in the vicinity of the flaw is intergranular. Fracture from the flaw or notch was intergranular in six of the nine polycrystalline alumina beams tested and this was assumed to indicate that the grain boundary chosen was sufficiently normal to the surface for the notch/flaw tip to lie on it. The remaining three specimens showed transgranular fracture, presumably because the grain boundary 
was inclined to the surface so that the flaw tip lay within a grain. These results are therefore not included in the grain boundary toughness values below.

\subsection{Apparent stress intensity factor at fracture $K_{\text {f(raw) }}$}

Almost all the load displacement curves were linear until sudden fracture at a well defined load. The apparent stress intensity factors at failure $K_{\text {f(raw) }}$ could then be calculated using Eqs. 1 and 2 . These raw values are given for tests conducted in air with the standard conditions used for FIBing notches and flaws in Table 1. Unless otherwise stated, errors quoted are the standard deviation of the results. Although the values for testing in air are similar to the values expected for fracture toughness, it will be shown below that this is to some extent coincidental and that quantitative interpretation needs allowance for various effects. As these are the same for all the results in Table 1, however, brief qualitative comparisons can be made here. It is evident that the notches and flaws give similar $K_{f(r a w)}$ values, supporting the validity of the measurements. Table 1 also shows that $K_{f(r a w)}$ is clearly lower when fracture initiates on the grain boundary than for fracture within the single crystal or grain of a polycrystal, as is expected in alumina, which usually exhibits intergranular fracture.

Three extrinsic factors were found to affect the results significantly:

1. Table 2 shows that the effect of notch tip radius: blunter notches gave higher raw $K_{f(\text { (raw) }}$ values.

2. The influence of testing environment is shown in Table 3.The exclusion of water by testing under oil significantly increased $K_{f(r a w)}$ compared with its value in air and conversely testing under water reduced $K_{f(\text { raw })}$. 
3. Finally, annealing the specimens before testing reduced $K_{f(\text { raw })}$ by approximately $2 \mathrm{MPa} \mathrm{m}^{1 / 2}$ for all annealing treatments and for both fracture on the diffusion bonded grain boundary and in the single crystal (Table 4). The notched and annealed single crystal specimens were the only results to display non-linear load displacement curves. The small deviation from linearity evident in Fig. 10 just before failure was present in all 9 such specimens. This was not seen in the results for annealed specimens notched on the diffusion bonded grain boundary.

\section{Discussion}

\subsection{Correction for notch tip radius}

It is evident that the notch tip radius, $\rho$, has an effect on the apparent toughness in sapphire (Table 2). Notch tip radius has not been identified as an important factor in previous work but most such reports are in metals, where there is more plastic deformation at the crack tip.

We analyse this using the approach of Fett [27] in which it is assumed that the blunt notch has a sharp incipient crack of length $\delta a$ ahead of it. The stress intensity at the tip of the incipient crack, $K_{t}$, is related to the apparent stress intensity factor for the notch, $K_{a p p}$, by:

$$
K_{t}=K_{a p p} \tanh (2 Y \sqrt{\delta a / \rho})
$$

where $Y$ is the appropriate geometrical factor for a short crack in uniform loading (the incipient crack can be assumed to be either a straight or a semicircular crack, with $Y=1.12$ or $2 / \pi$ respectively [28]). Equation 5 can be fitted to the results with $K_{t}$ and $\delta a$ as adjustables on the assumption that these are independent of the tip radius. The quality of the fit and the value of $K_{t}$ do not depend on the choice of incipient crack shape. Figure 11 shows the fit is good for fracture on the $m$-plane and the value of $K_{t}$ at fracture is $3.5 \mathrm{MPa} \mathrm{m} \mathrm{m}^{1 / 2}$. The incipient crack length $\delta a$ is $7 \mathrm{~nm}$ if it assumed to be straight and $17 \mathrm{~nm}$ for a semicircular crack. Very similar results were obtained for fracture nominally on the $c$-plane. For the 
smallest notch radius of $15 \mathrm{~nm}$ used in all other measurements reported here, the correction factor for the notch radius is relatively small at 0.9 .

\subsection{Correction for residual stresses}

Even when corrected for notch radius as above, the apparent toughness on the $m$-plane under oil of 5.4 $\mathrm{MPa} \mathrm{m}^{1 / 2}$ is $70 \%$ higher than Iwasa and Bradt's macroscopic value for fracture toughness $K_{c}$ of $3.14 \mathrm{MPa}$ $\mathrm{m}^{1 / 2}$ [25]. Considered along with the substantial reduction of about $2 \mathrm{MPa} \mathrm{m}^{1 / 2}$ in apparent toughness of both the bulk single crystal and the diffusion bonded grain boundary on annealing, this strongly suggests that the compressive residual stresses caused by Ga ion implantation and described in Section 3.3 increase the apparent toughness.

We further examine this possibility by estimating the compressive stress $\sigma_{R}$ required to produce the observed stress shielding $\Delta K_{R} \approx-2 \mathrm{MPa} \mathrm{m}^{1 / 2}$ when acting on the incipient crack at the notch root estimated above. Assuming the stress to be uniform in the implanted zone for simplicity:

$$
\sigma_{R}=\frac{\Delta K_{R}}{Y \sqrt{\pi \delta a}}
$$

where $Y$ is the appropriate factor for the assumed crack geometry. Various combinations of $Y$ and $\delta a$ can be assumed but the extreme values are obtained by assuming a straight $\operatorname{crack}(\delta a=7 \mathrm{~nm})$ and either $Y=$ 1.12 (i.e. treating $\delta a$ as an edge crack within the blunt notch) or $Y=2^{3 / 2} / \pi$ (which corresponds to a long straight crack loaded uniformly over distance $\delta a$ from the crack tip). The resulting range for $\sigma_{R}=-12$ to $15 \mathrm{GPa}$, which is consistent with the value of $-16 \pm 6 \mathrm{GPa}$ estimated from curvature measurements in Section 3.3. Although the actual depth profile of surface stress and the effect of the notch tip geometry on its magnitude need further investigation, this good agreement further reinforces the idea that the residual stresses restrain fracture initiation and increase the apparent toughness. 
The cross sections of the unannealed notch tips in Fig. 4 do not reveal any incipient cracks around the notch tip, although the compressive residual stress in the implanted region would tend to close any such cracks. The more uneven appearance of the notch tips of the annealed specimens (Fig. 7) suggests the presence of defects at the notch surfaces although these cannot be identified unequivocally in this rather thick specimen. Regardless of the origin of the defects, the similarity of the $\delta a$ values to the thickness of the implanted layer in these unannealed samples and their sudden failure at the initiation of fracture suggests that the critical step in crack initiation is escape of the incipient crack from the compressive implanted region at the notch tip, in which case the initial length of the incipient crack is irrelevant providing it is shorter than the implantation depth. The rapid acceleration of the crack tip once it escapes beyond the compressive zone is demonstrated by the hackle around the FlBed flaws in the fracture surfaces (Fig. 9c) and the increasing hackle with notch radius is the result of the corresponding increase in overloading at fracture (Fig. 9b).

The more diffuse nature of the fracture event in the annealed straight crack specimens (Fig. 10) is also consistent with this view: annealing is presumed to have removed the residual stresses so the only reason for an increase in stress intensity factor is the developing size and shape of the crack. The small amount of stable crack growth may arise because the initial development of crack shape gives some stability. Subcritical crack growth may also contribute to the stability as is discussed in Section 4.3. The lack of a pop-in event in Fig. 10 suggests that crack initiation at the FlBed notch tips is relatively easy if the residual stress is removed by annealing.

Several aspects of this analysis of the fracture process would benefit from further investigation. The residual stress has been assumed to be constant through the implanted region but in reality is likely to vary with depth. The residual stress was measured on an approximately planar surface in-plane stress but the notch tip is curved and closer to plane strain. Further analysis not shown here indicates that these two factors partially annul one another. 
These conclusions contrast with recent results on silicon, which appear to show no effect of residual stress or other beam damage effects $[6,7]$. This suggests that the effect of ion implantation may be material-dependent. One possible explanation is that the more open, covalently bonded structure of $\mathrm{Si}$ is better able to tolerate implanted ions without excessive strain being produced than the comparatively close packed structure of $\alpha-\mathrm{Al}_{2} \mathrm{O}_{3}$. Support for this idea comes from the work of Kalyanasundaram et al. [29] whose molecular dynamics simulations showed that the surface residual stress under medium energy bombardment of silicon with argon ions saturates at less than $2 \mathrm{GPa}$, which is significantly less than the experimental values of Burnett and Page for Argon ion implantation [20] in sapphire mentioned in Section 3.3, albeit with higher incident energies. Alternatively, the mechanism of crack initiation at the notch tip in silicon - an incipient crack, shear band or local phase transformation for example - may occur over a length scale greater than the thickness of the implanted layer so that the associated residual stress has less effect. Unlike $\alpha-\mathrm{Al}_{2} \mathrm{O}_{3}$, silicon is well known to be capable of undergoing phase transformations or amorphisation under high stress [20,30-32].

The results of Jaya et al. [6] similarly show no apparent effect of notch tip radius in silicon. A different mechanism of crack initiation to that in $\alpha-\mathrm{Al}_{2} \mathrm{O}_{3}$ may also be consistent with this finding. It is also noted that although the notch tip radius sensitivity reported here has been interpreted in terms of the propagation of incipient cracks in section 4.1, the geometrical modification of the residual stress level at the notch tip by the radius may also be involved, in which case the different notch tip radius responses in silicon and $\alpha-\mathrm{Al}_{2} \mathrm{O}_{3}$ would also be consistent with the difference in residual stress response.

The material dependence of the effect of implantation stress and notch radius on toughness measurements may be relevant to the toughness values measured by Tatami et al. in $\mathrm{Si}_{3} \mathrm{~N}_{4}$ [7], which were found to be higher than expected from ab initio calculations and surface energy considerations.

\subsection{Correction of stress intensity factors for residual stress and notch tip radius}


Although there are several issues worthy of further investigation, the reasonable agreement in residual stresses measured from curvature and deduced from the fracture results, and the similar reduction in apparent toughness on annealing for the specimens notched at the diffusion bonded grain boundary and within the single crystal, suggest that the above view of the fracture process provides a method of correcting the results for the effects of implantation stress and notch bluntness. Combining Eqs. 5 and 6 , the true crack tip stress intensity at failure, $K_{f(c o r)}$ is given by:

$$
K_{f(c o r)}=K_{f(\text { raw })} \tanh (2 Y \sqrt{\delta a / \rho})+\Delta K_{R}
$$

Table 5 summarises the results for $10 \mathrm{pA}$ notches and flaws ( $15 \mathrm{~nm}$ notch radii) corrected for notch bluntness by applying the correction factor of $\tanh (2 Y \sqrt{\delta a / \rho})=0.9$ derived in section 4.1 and then, for unannealed specimens, including $\Delta K_{R}=-1.9 \mathrm{MPa} \mathrm{m}^{1 / 2}$, this being the mean difference between the notch tip-corrected values for the corresponding annealed and unannealed results for fracture of the single crystal and the diffusion bonded grain boundary. This assumes (i) that the annealing treatments completely removed the implantation stress, which is reasonable given the similar results for different annealing temperatures (Table 4), and (ii) that both the unannealed and annealed specimens contained incipient cracks similar in size to the depth of the implantation, as discussed in the previous section.

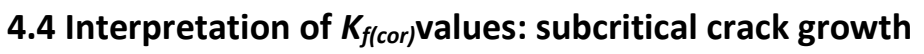

Table 5 shows that the corrected fracture stress intensity $K_{f(c o r)}$ for $m$-plane sapphire in oil was $3.5 \pm 0.2$ $\mathrm{MPa} \mathrm{m}^{1 / 2}$. This is now in reasonable agreement with the corresponding $K_{c}$ measured by Iwasa and Bradt of 3.14 +/- $0.30 \mathrm{MPa} \mathrm{m}^{1 / 2}$, though somewhat higher than the value of Wiederhorn $\left(2.6+/-0.3 \mathrm{MPa} \mathrm{m}^{1 / 2}\right.$ $[26,33,34])$. Given the nature of the corrections, the wide disparity between literature values from macroscopic tests and the fact that our value is based on only two results measured under oil, the level of agreement is reasonable and demonstrates the viability of the technique. 
The much lower $K_{f(c o r)}$ values for all the specimens tested in air and the further reduction when testing under water demonstrate unequivocally that the results were affected by moisture assisted subcritical crack growth (SCG). The influence of SCG on strength and toughness tests has been analysed by Evans [35] and, ignoring for the moment the complication of residual stress, this provides a good starting point for discussion. For cracks which are short compared with the specimen thickness, as in the initial conditions for our specimens, a constant stress-rate $\dot{\sigma}$, no crack growth below a threshold stress intensity $K_{0}$ and crack growth rate $V=A K^{n}$ in Regime I, the applied stress $\sigma$ tends asymptotically to a limiting value $\sigma^{*}$ as the crack grows when $n$ is high:

$$
\sigma^{*}=\frac{K_{0}}{Y \sqrt{\pi a_{0}}}\left[1+\frac{2 Y \sqrt{\pi} \dot{\sigma} a_{0}^{3 / 2}(n+1)}{V_{0} K_{0}(n-2)}\right]^{\frac{1}{n+1}}
$$

where $a_{0}$ is the initial crack length, and $V_{0}$ is the crack growth rate when $K$ just exceeds $K_{0}$. (Note that $Y$ in this equation is defined according to the notation in eqs. 5 and 6 and is different from the definition of $Y$ in Evans [35] by a factor of $1 / \sqrt{\pi}$ ). For results on the $m$-plane in air, Asoo et al. [36] give $K_{0}=1.64$ MPa $\mathrm{m}^{1 / 2}, n=45.6$ and $A=1.810^{-20} \mathrm{~m} / \mathrm{s} \cdot\left(\mathrm{MPa} \mathrm{m}^{1 / 2}\right)^{-\mathrm{n}}$, yielding $V_{0}=1.110^{-10} \mathrm{~m} \mathrm{~s}^{-1}$. With typical values $a_{0}=$ $0.3 \mu \mathrm{m}, Y=1$ and $\dot{\sigma}=10 \mathrm{MPa} \mathrm{s}^{-1}, \sigma^{*}=1.08 \frac{K_{0}}{Y \sqrt{\pi a_{0}}}$. For these simple assumptions, therefore, the value of $K_{f(c o r)}$ calculated from the initial crack length and the stress at which crack growth is first detected (e.g. as a departure in linearity of the loading curve) should be equal to the threshold stress intensity for subcritical crack growth, $K_{0}$, to within $8 \%$ as a worst case. This result arises because once the crack begins to grow, fracture ensues so rapidly that the stress does not have time to change significantly at the loading rates used. Although our specimens were actually tested with a constant displacement (strain) rate rather than constant loading (stress) rate, all our $K_{f(c o r)}$ measurements were taken in conditions where the load-displacement curve was linear. In this case, the notch is still short 
compared with the beam thickness, constant strain rate is equivalent to constant stress state and the equation remains valid. Restriction of the analysis to the linear region, where slow and stable loading is occurring, also avoids problems with nanoindenter instability which can occur under rapidly changing conditions.

The majority of our results conform essentially to this simple picture, although some further qualification is needed for each category of specimen. The use of a relatively blunt notch strictly requires modification of eq. 8 , which assumes a sharp crack, but under the present assumption that there is an incipient crack ahead of the notch at the point where $K$ is calculated, the required correction via eq. 5 is small.

The presence of a residual stress in the unannealed specimens restrains crack growth whilst the incipient crack is within the implanted layer. As the crack emerges from the implanted zone, $K_{t} \approx K_{0}$ as in the simple picture above but once it escapes from the compressed zone the ensuing failure is even more rapid than eq. 8 suggests, giving even less time for the stress to change from its value at the onset of crack propagation, and a $K_{f(c o r)}$ value correspondingly closer to $K_{0}$.

The annealed single crystal specimens were the only samples to show non-linearity in the load displacement curves before failure. This may be because the absence of the residual stress and the constant displacement rate conditions allowed a greater degree of subcritical crack growth to occur before failure. In this case, eq. 8 ceases to be valid for constant displacement rate because $Y$ becomes a function of crack length $a$ as the crack grows to a significant fraction of the specimen thickness and $\dot{\sigma}$ reduces as the specimen becomes more compliant. Evans [35] shows that a range of different scenarios can occur in this case. For the present results, however, it is emphasised that the $K_{f(c o r)}$ values were measured at the end of the linear region before significant crack growth had occurred, where eq. 8 remains valid. The $K_{f(c o r)}$ values calculated are therefore also expected to be close to $K_{0}$ as above. (In any 
case, the change in load in the non-linear portion is Fig. 10 is small. Estimates of the crack growth rates in the non-linear region made by calculating the crack length at each data point from the compliance gave values of $V \sim 10^{-7} \mathrm{~ms}^{-1}$. Comparison with the results of Wiederhorn [2,34] suggests that $K$ would still be close to $K_{0}$ with this value of $V$ even in the non-linear region in these experiments).

The annealed specimens notched at the diffusion bonded grain boundary exhibited sudden brittle fracture. This is presumably because of differences in the subcritical crack growth on grain boundaries compared with fully crystalline material. Although the precise values of $K_{0}$ and $V_{0}$ for grain boundary fracture will differ from the single crystal values of Asoo et al. [36] used above, it is unlikely that they will differ by so much as to invalidate the conclusion that the $K_{f(c o r)}$ measurements are close to $K_{0(\mathrm{gb})}$, the threshold stress intensity factor for subcritical crack growth on the grain boundary.

A final point to discuss in the interpretation of these results is the extent to which they represent undamaged materials as opposed to material damaged by ion implantation. Section 3.2 showed that the amount of Ga implanted is low and the implanted region has the same crystal structure as the undamaged material below. The analysis above suggests that fracture takes place when the incipient crack emerges from the implanted zone. Thus, at the point at which $K_{f(c o r)}$ is measured, the crack tip is in the undamaged material. It is likely that, if anything, the implanted region has a lower toughness than the undamaged material beyond it, which would also support the idea that the point of fracture gives a valid measurement of the properties of the bulk ceramic, which is more difficult for the crack to penetrate.

The analysis in Sections $4.1-4.4$ makes several assumptions which, though reasonable, cannot be directly verified. In particular, the assumption that there is either a pre-existing incipient crack at the notch root or that initiation at the root precedes failure (rather than failure occurring suddenly and directly from the notch root) remains open to question. The next section, however, adds support to the 
conclusions drawn by showing that the results of the analysis are in reasonable agreement not only with one another, but with literature values as well.

\subsection{Comparison of $K_{0}$ values with literature}

Literature values for subcritical crack growth are sparse and show wide variations. This is at least partly because of the difficulty of investigating such low crack growth rates with macroscopic specimens. We know of no data for subcritical crack growth on the a-plane of sapphire in air nor for crack growth on individual grain boundaries in alumina. There is general agreement that $K_{0}$ reduces as the local concentration of water increases [2,34]. Our experiments agree with this conclusion: the value of $0.9+/-$ $0.2 \mathrm{MPa} \mathrm{m}^{1 / 2}$ measured here for fracture in water on the $m$-plane is significantly less than our corresponding value in air of $1.5+/-0.3 \mathrm{MPa} \mathrm{m}{ }^{1 / 2}$, which is in turn significantly less than that in oil. This value of $K_{0}$ for the $m$-plane in air agrees to within the scatter with that of Asoo et al. [36] who estimated a $K_{0}$ of $1.64 \mathrm{MPa} \mathrm{m}^{1 / 2}$.

The present results show that $K_{0}$ for fracture on the $a$-plane is similar to the $m$-plane value (Table 5 ). Although there are no direct measurements of $K_{0}$ on the $a$-plane in the literature, related measurements such as the fracture toughness measured under water, summarised in [33] lead to the same conclusion. The apparently similar value for fracture on the $c$-plane obtained here is attributed to a combination of the lower $K_{0}$ for the $r$-plane [33], on which fracture is actually thought to initiate (Section 3.4) and the reduced crack driving force resulting from the accompanying tilt and twist out of the plane of the FIBed notch or flaw.

The mean $K_{0}$ values from individual grains in the polycrystalline alumina were similar to the single crystal values. Similarly, the values for individual grain boundaries in polycrystalline alumina agree well with those from the bicrystal. There are no literature values for subcritical crack growth in alumina grain boundaries with which to compare our results. However, the fact that the $K_{0}$ values are significantly 
lower (by a factor of 2) than the single crystal values is consistent with the idea that the grain boundary, being a defective area of crystal, needs less energy to fracture.

It is interesting to note that the chevron notch measurements of Mueller et al. [8] on nanocrystalline alumina and fused quartz were unaffected by slow crack growth despite the fact that the loading rates used were not sufficient to avoid it, at least in the limit of easy crack initiation [37]. The reason for the absence of SCG for the chevron notch results is unknown [37] but the clear observation of an environmental effect on crack propagation in the present microcantilever tests demonstrates the need for further research to understand the conditions under which SCG operates.

The ability of microcantilever experiments to investigate very slow crack growth rates makes them ideal for studying subcritical crack growth. Sustained loading is experienced in most applications of ceramics. $K_{0}$ is therefore a better design criterion than $K_{c}$ but has seldom been measured because of the experimental difficulties involved. Microcantilever measurements such as these should be invaluable in designing ceramic components where a long life under load is important.

\section{Conclusions}

1. Stress intensity factors at fracture $K_{f}$ have been measured in $\mathrm{Al}_{2} \mathrm{O}_{3}$ using microcantilevers containing FIBed notches and artificial flaws. Measurements have been made for single crystals on various crystallographic planes, the grain boundary of a diffusion bonded bicrystal and individual, pre-selected grain boundaries of polycrystals of $\mathrm{Al}_{2} \mathrm{O}_{3}$ for the first time. 
2. The notch tip radius had a significant effect on the apparent $K_{f}$. Correction was made by the method of Fett $[27,28]$ but was a relatively small factor with optimally milled notches (tip radius $\sim 15 \mathrm{~nm}$ ).

3. The apparent $K_{f}$ was increased substantially by residual stress at the notch tip caused by Ga-ion implantation (12-15 GPa over a depth of $\sim 20 \mathrm{~nm}$ ). This problem can be avoided either by calibrating the effect of the residual stresses or by annealing the stresses out prior to testing.

4. When corrected for notch tip radius and implantation stress, $K_{f}$ represented the fracture toughness $K_{c}$ if moisture is excluded by testing under silicone oil. In air or under water, the $K_{f}$ values are close to the threshold stress intensity for subcritical crack growth, $K_{0}$. Although the crack initiation process needs further investigation, the results are consistent with one another and are in good agreement with literature values from macroscopic specimens.

5. $K_{0}$ for individual alumina grain boundaries was directly measured for the first time. The mean value was $0.7 \pm 0.2 \mathrm{MPa} \mathrm{m}^{1 / 2}$ in air. $K_{0}$ for fracture on the $m$ - or $a$-plane was $1.5 \pm 0.2 \mathrm{MPa} \mathrm{m} \mathrm{m}^{1 / 2}$ in air and $0.9 \pm$ $0.2 \mathrm{MPa} \mathrm{m}^{1 / 2}$ in water.

\section{Acknowledgements}

The contributions of Dr DEJ Armstrong and Dr G Hughes in training AN in the experimental techniques involved in the production and testing of microcantilever beams and useful discussions with Prof. S.G. Roberts are gratefully acknowledged. The work was funded by the EPSRC via the Oxford Department of Materials Doctoral Training Account. 


\section{References}

[1] Davidge R. Mechanical behaviour of ceramics. Cambridge: CUP; 1979

[2] Lawn BR. Fracture of brittle solids - second edition. Cambridge: CUP; 1993.

[3] Johansson S, Schweitz J-A, Tenerz L, Tirén J. Fracture testing of silicon microelements in situ in a scanning electron microscope. J App Phys 63 (1988) 4799-4803.

[4] Weihs TP, Hong S, Bravman JC, Nix WD. Mechanical deflection of cantilever microbeams: a new technique for testing the mechanical properties of thin films. J Mater Res 3 (1988) 931-942.

[5] Di Maio D, Roberts SG. "Measuring fracture toughness of coatings using focused-ion-beam-machined microbeams." J Mater Res 20 (2005) 299-302.

[6] Jaya BN, Kirchlechner C, Dehm G. Can microscale fracture tests provide reliable fracture toughness values? A case study in silicon G. J. Mater. Res. 30 (2015) 686-698.

[7] Tatami J, Katayama M, Ohnishi M,Yahagi T, Takahashi T, Horiuchi T et al. Local Fracture Toughness of $\mathrm{Si}_{3} \mathrm{~N}_{4}$ Ceramics Measured using Single-Edge Notched Microcantilever Beam Specimens. J. Am. Ceram. Soc. 98 (2015) 965-971.

[8] Mueller MG, Pejchal V, Žagar G, Singh A, Cantoni M, Mortensen A. Fracture toughness testing of nanocrystalline alumina and fused quartz using chevron-notched microbeams. Acta Mater 86 (2015) 385-395.

[9] Cliff G, Lorimer GW. The Quantitative Analysis of Thin Specimens. Journal of Microscopy 103 (1975): 203-207.

[10] Mendelson MI. Average grain size in polycrystalline ceramics." J. Am. Ceram. Soc. 52 (1969) 443446.

[11] Armstrong DEJ, Wilkinson AJ, Roberts SG. Micro-mechanical measurements of fracture toughness of bismuth embrittled copper grain boundaries. Phil Mag Lett 91 (2011) 394-400.

[12] Strobl S, Supancic P, Lube T, Danzer R. Surface crack in tension or in bending - a reassessment of the newman and raju formula in respect to fracture toughness measurements in brittle materials. J. Eur. Ceram. Soc. 8 (2012) 1491-1501.

[13] Stoney GG. The Tension of Metallic Films Deposited by Electrolysis. Proc Roy Soc. A vol 82, no 553 (1909) 172-175.

[14] He J and Clarke DR. Determination of the Piezospectroscopic Coefficients for Chromium-Doped Sapphire. J. Am. Ceram. Soc. 78 (1995) 1347-1353.

[15] Kiener D, Motz C, Rester M, Jenko M, Dehm G. FIB Damage of Cu and Possible Consequences for Miniaturized Mechanical Tests. Mat Sci and Eng: A 459 (2007) 262-272.

[16] Dehm G, Motz C, Scheu C, Clemens H, Mayrhofer PH, and Mitterer C. Mechanical Size-Effects in Miniaturized and Bulk Materials. Adv Eng Mat 8 (2006) 1033-1045. 
[17] Bei H, Shim S, Miller MK, Pharr GM, and George EP. Effects of Focused Ion Beam Milling on the Nanomechanical Behavior of a Molybdenum-alloy Single Crystal. App Phys Lett 91 (2007) 111915111915-3.

[18] Hill VG, Roy R, and Osborn EF. The System Alumina-Gallia-Water. J Am Ceram Soc 35 (1952) 135142.

[19] Galazka Z, Uecker R, Irmscher K, Albrecht M, Klimm D, Pietsch M, Brützam M, BertramR, Ganschow $S$, Fornari R.. Czochralski growth and characterization of $\beta-G a 2 O 3$ single crystals. Cryst. Res. Technol. 45 (2010) $1229-1236$

[20] Burnett PJ, Page TF. An Investigation of Ion Implantation-induced Near-surface Stresses and Their Effects in Sapphire and Glass. J Mat Sci 20 (1985) 4624-4646.

[21] Gnaser H, Brodyanski A, Reuscher B, Focused ion beam implantation of Ga in Si and Ge: fluence-dependent retention and surface morphology. Surf Interface Anal, 40 (2008) 1415-1422.

[22] Prével B, Benoit J-M, Bardotti L, Mélinon P, Ouerghi A, Lucot D, Bourhis E, and Gierak J.

Nanostructuring graphene on SiC by focused ion beam: effect of the ion fluence. App Phys Lett 99 (2011) 083116.

[23] Wachtman JB, Cannon WR, Matthewson MJ. Mechanical Properties of Ceramics. Hoboken NJ: Wiley; 2009.

[24] Tsirk A, Fractography Lessons from Knapping. In Fractography of Glasses and Ceramics VI, Hoboken NJ: Wiley; 2012. pp. 123-132.

[25] Iwasa M and Bradt RC. Fracture Toughness of Single-Crystal Alumina. Advances in Ceramics 10: Structure and Properties of MgO and Al2O3 Ceramics. Columbus OH: Am Ceram Soc; 1984. pp. 767-779.

[26] Wiederhorn SM. Fracture of Sapphire. J. Am. Ceram. Soc. 52 (1969) 484-491.

[27] Fett T and Munz D. Stress Intensity Factors and Weight Functions. Southampton: Computational Mechanics Publications; 1997.

[28] Damani R, Gstrein R, and Danzer R. Critical Notch-root Radius Effect in SENB-S Fracture Toughness Testing. J Eur Ceram Soc 16 (1996) 695-702.

[29] Kalyanasundaram N, Wood M, Freund JB, Johnson HT. Stress evolution to steady state in ion bombardment of silicon. Mechanics Research Communications 35 (2008) 50-56.

[30] Han Z, Zheng K, Zhang YF, Zhang Z, and Wang ZL. Low temperature in-situ large strain plasticity of silicon nanowires. Adv. Mater. 19 (2007) 2112-2118.

[31] Oestlund F, Rzepiejewska-Malyska K, Leifer K, Hale LM, Tang Y, Ballarini R, Gerberich WW, Michler J. Brittle to ductile transition in uniaxial compression of silicon pillars at room temperature. Adv. Funct. Mater. 19 (2009) 2439-2444.

[32] Gerberich WW, Stauffer DD, Beaber AR, and Tymiak NI. A brittleness transition in silicon due to scale. J. Mater. Res. 27 (2012) 552-567. 
[33] Salem JA. Slow Crack Growth and Fracture Toughness of Sapphire for the International Space Station Fluids and Combustion Facility. 2006. NASA Technical Report NASA/TM-2006-214023, E-15338.

[34] Wiederhorn SM. Fracture of Ceramics. In National Bureau Special Publication 303, Proceedings of the conference on Mechanical and Thermal Properties of Ceramics, April 1-2, Gaithersburg, MD, 1968. pp. 217-241.

[35] Evans AG. Slow crack growth in brittle materials under dynamic loading conditions. Int. J. Frac. 10 (1974) 251-259.

[36] Asoo B,McNaney JM, Mitamura Y, Ritchie RO. Cyclic fatigue-crack propagation in sapphire in air and simulated physiological environments. J Biomed Mater Res 52 (2000) 488-491

[37] Žagar G, Singh A, Pejchal V, Mueller MG; Mortensen A. On measuring fracture toughness under load control in the presence of slow crack growth. J. Eur. Ceram. Soc. 35 (2015) 3155-3166

[38] Munz D, Bubsey RT, Shannon JL. Fracture toughness determination of $\mathrm{Al}_{2} \mathrm{O}_{3}$ using four-point-bend specimens with straight-through and chevron notches." J. Am. Ceram. Soc. 63, (1980) 300-305.

\section{Appendix: Stress intensity factor for edge-notched triangular cross-section beams.}

For very short notches, the stress intensity factor $K$ can be estimated using the Euler-Bernoulli beam theory in conjunction with the standard fracture mechanics equation for the stress intensity factor for an edge-notch under uniform loading:

$$
K=\frac{12 F L_{n}}{w h^{2}} \cdot 1.12 \sqrt{\pi \alpha} \quad \alpha<<\quad \text { A1 }
$$

where $F$ is applied force, $L_{n}$ is the distance between the loading point and the notch and the other variables are the dimensions shown in Fig. A1. When $\alpha$ is a significant proportion of $h$, however, both the geometry and the load distribution complicate the situation and numerical analysis is needed. We use a variation on the compliance analysis method (see [38] for example) in conjunction with finite element analysis.

For a linear elastic specimen, the increment of mechanical energy of the system when the crack grows by an increment $d \alpha$ is: 
$d U_{m}=-\frac{1}{2} F^{2} d C$

where $\mathrm{d} C$ is the corresponding change in compliance. The mechanical energy release rate is:

$G=-\frac{d U_{m}}{d A}$

where $A$ is the crack area, and referring to Fig. A1,

$d A=w \frac{h-\alpha}{h} d \alpha$

Combining A2-A4:

$G=\frac{F^{2}}{2 w} \cdot \frac{h}{h-\alpha} \cdot \frac{d C}{d \alpha}=\frac{F^{2}}{E^{\prime} h^{2} w} \cdot \frac{1}{1-\alpha^{\prime}} \cdot\left(\frac{1}{2} \frac{d C^{\prime}}{d \alpha^{\prime}}\right)$

where $E$ is the effective Young's modulus and $\alpha^{\prime}$ and $C^{\prime}$ are the dimensionless crack length $\alpha / h$ and dimensionless compliance $C E h$ respectively. Using $K=\sqrt{G E^{\prime}}$, the stress intensity factor is:

$K=\frac{F}{h \sqrt{w}} \cdot\left(\frac{1}{1-\alpha^{\prime}}\right)^{\frac{1}{2}} \cdot\left(\frac{1}{2} \frac{d C^{\prime}}{d \alpha^{\prime}}\right)^{\frac{1}{2}}=\frac{F}{h \sqrt{w}} \cdot\left(\frac{1}{1-\alpha^{\prime}}\right)^{\frac{1}{2}} \cdot Y^{\prime} \quad \cdot \quad$ A6

Finite element models of the notched beam have been generated discretising a geometry representative of our experiments (i.e. beam length $30 \mathrm{~mm}, h=2.5 \mathrm{~mm}$, and $w=4.2 \mathrm{~mm}$ ). The commercial software LS-Dyna was used to perform a parametrical analysis of the effect of $\alpha^{\prime}$ over $Y^{\prime}$. The load was applied $20 \mathrm{~mm}$ from the built-in end, and the material was modelled as isotropic linear elastic with Young's modulus $398 \mathrm{GPa}$ and Poisson's ratio 0.22. The numerical prediction of the compliance of the un-notched beam was validated against the analytical Euler-Bernoulli solution, showing a maximum error of $0.07 \%$. 
For varying notch positions sufficiently far from the fixed end, $Y^{\prime}$ was found to be proportional to $L_{n}$ for constant $\alpha^{\prime}$, as would be expected for eq. A6 with the local stress level determined by the bending moment. The results were therefore described by fitting a $4^{\text {th }}$ degree polynomial in $\alpha^{\prime}$ to $Y^{\prime} / L_{n}$ and constraining the constant term such that eq. A6 reduces to eq. A1 for small $\alpha^{\prime}$. We give here the result for notches positioned at $0.2 L_{n}$ from the built-in end, which is typical of our experiments:

$$
K=\frac{12 F L_{n}}{w h^{2}} \cdot 1.12 \sqrt{\pi \alpha}\left(1+0.123 \alpha^{\prime}+5.456 \alpha^{\prime 2}+0.073 \alpha^{\prime 3}-0.023 \alpha^{\prime 4}\right)
$$

The equation gives an excellent fit to the model for $0<\alpha^{\prime}<0.4$. For notch positions increasing from 0.2 up to $0.5 L_{n}$ from the built-in end the maximum variation in $K$ in the model is less than $2.5 \%$. When the notch position is moved to $0.1 L_{n}$, the equation overestimates $K$ by about $5.5 \%$.

\section{Figure captions}

Figure 1. Un-notched microcantilever beam in diffusion bonded sapphire: a) the free end, tilted to $50^{\circ}$, and $b$ ) the beam in its trench before loading. The line crossing the beam near the built-in end is the thermally etched grain boundary.

Figure 2. Schematic of curvature experiment for estimating implant stresses (not to scale).

Figure 3. TEM micrograph of DB grain boundary at the surface of the bicrystal.

Figure 4. TEM of FIB milled notches, filled with platinum from the specimen preparation, at the surface of sapphire at beam currents of: a) 10pA, b) 100pA, and c) 1000pA.

Figure 5. (a) HRTEM of implanted surface showing lattice fringes and thin layer ( $2 \mathrm{~nm}$ ) of redeposited material. (b) $[10 \overline{1} 0]$ nanobeam diffraction pattern from implanted layer.

Figure 6. Increase in hardness of c-plane sapphire after imaging in the FIB relative to unimplanted material as a function of indentation depth. Different symbols are from two different regions of the specimen. Each point represents the average value at the relevant depth from 25 indentations. 
Figure 7. Cross-sectional TEM image of the notch annealed in vacuum.

Figure 8. $R 1 \mathrm{Cr}^{3+}$ fluorescence peak position along a line scan normal to the ion implanted edge of the FIB lift out specimen. The implanted edge is at $y=-2 \mu \mathrm{m}$. The gradient of dotted line was used in eq. 4 to calculate the curvature.

Figure 9. Fracture surfaces of different types of microcantilever beam. (a) Fracture on $m$ plane showing smooth, straight-through fracture. (b) As for (a) but with blunt notch (radius $=76 \mathrm{~nm}$ ) showing hackle and "cantilever curl". (c) Fracture from small FIBed flaw (inset) on a plane. (d) Specimen orientated for fracture on $c$ plane showing heavily facetted fracture surface. (e) Fracture surface from notched DB grain boundary. (f) Fracture from flaw (arrowed) FIBed on grain boundary of polycrystalline alumina showing intergranular fracture in the vicinity of the fracture origin.

Table 1. Raw values for stress intensity at fracture $K_{\text {f(raw) }}$ in air at room temperature with $10 \mathrm{pA}$ FIBed notches or flaws. SD is the standard deviation of the measurements. \# is the number of measurements. *The $c$ plane fracture surface was facetted i.e. the local fracture was on non-basal crystal planes.

\begin{tabular}{|c|c|c|c|c|c|c|}
\hline & 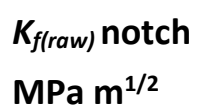 & $\begin{array}{l}\text { SD } \\
\mathrm{MPa} \mathrm{m}^{1 / 2}\end{array}$ & $\#$ & $\begin{array}{l}K_{f(\text { raw) }} \text { flaw } \\
\mathrm{MPa} \mathrm{m}^{1 / 2}\end{array}$ & $\begin{array}{l}\text { SD } \\
\mathrm{MPa} \mathrm{m}^{1 / 2}\end{array}$ & $\#$ \\
\hline \multicolumn{7}{|l|}{ single crystals } \\
\hline fracture on $\mathrm{m}$ plane & 3.7 & 0.3 & 7 & - & - & - \\
\hline fracture on a plane & 3.7 & 0.2 & 6 & 3.7 & 0.3 & 2 \\
\hline fracture on c plane* & 3.7 & 0.2 & 11 & 4.3 & - & 1 \\
\hline bicrystal grain boundary & 2.9 & 0.3 & 8 & 2.7 & 0.6 & 5 \\
\hline \multicolumn{7}{|l|}{ polycrystalline } \\
\hline fracture on gb (intergranular) & 3.0 & - & 1 & 2.8 & 0.3 & 5 \\
\hline fracture in grain (transgranular) & - & - & - & 3.9 & 0.2 & 3 \\
\hline
\end{tabular}


Table 2. Influence of notch tip radius on apparent stress intensity factor at failure $K_{f(\text { (raw) }}$ for tests conducted in air. SD is the standard deviation of the measurements. \# is the number of measurements. *The $c$ plane fracture surface was facetted i.e. the local fracture was on non-basal crystal planes.

\begin{tabular}{|c|c|c|c|c|c|c|}
\hline & \multicolumn{3}{|c|}{$m$ plane fracture } & \multicolumn{3}{|c|}{ c plane fracture* } \\
\hline $\begin{array}{l}\text { tip radius } \\
\mathrm{nm}\end{array}$ & $\begin{array}{l}K_{\text {f(raw) }} \text { notch } \\
\mathrm{MPa} \mathrm{m}^{1 / 2}\end{array}$ & $\begin{array}{l}\mathrm{SD} \\
\mathrm{MPa} \mathrm{m}^{1 / 2}\end{array}$ & \# & $\begin{array}{l}K_{\text {f(raw) }} \text { flaw } \\
\mathrm{MPa} \mathrm{m}^{1 / 2}\end{array}$ & $\begin{array}{l}\text { SD } \\
\mathrm{MPa} \mathrm{m}^{1 / 2}\end{array}$ & $\#$ \\
\hline 15 & 3.8 & 0.3 & 4 & 3.8 & 0.2 & 6 \\
\hline 32 & 4.6 & 0.3 & 4 & 4.7 & 0.2 & 3 \\
\hline 76 & 5.9 & 0.2 & 3 & 6.0 & 0.4 & 3 \\
\hline
\end{tabular}


Table 3. Influence of testing environment on apparent stress intensity factor at failure $K_{f(\text { (raw) }}$ with $10 \mathrm{pA}$ FIBed notches. Fracture was on the single crystal $m$ plane. SD is the standard deviation of the measurements. \# is the number of measurements.

\begin{tabular}{|c|c|c|c|}
\hline testing environment & $\begin{array}{l}K_{\text {f(raw) }} \text { notch } \\
\text { MPa m }^{1 / 2}\end{array}$ & $\begin{array}{l}\text { SD } \\
\mathrm{MPa} \mathrm{m}^{1 / 2}\end{array}$ & $\#$ \\
\hline water & 3.2 & 0.2 & 4 \\
\hline air & 3.7 & 0.3 & 7 \\
\hline silicone oil & 6.0 & 0.3 & 2 \\
\hline
\end{tabular}


Table 4. Influence of annealing on apparent stress intensity factor at failure $K_{\text {f(raw) }}$ with $10 \mathrm{pA}$ FIBed notches or flaws. SD is the standard deviation of the measurements. \# is the number of measurements. *The $c$ plane fracture surface was facetted i.e. the local fracture was on non-basal crystal planes.

\begin{tabular}{|l|r|r|r|}
\hline & $\begin{array}{l}\boldsymbol{K}_{\text {f(raw) }} \text { notch } \\
\text { MPa m }^{\mathbf{1 / 2}}\end{array}$ & $\begin{array}{l}\text { SD } \\
\mathbf{M P a ~ m}^{\mathbf{1 / 2}}\end{array}$ & \multicolumn{1}{l|}{} \\
\hline Fracture on c plane* & & & \\
\hline as milled & 3.7 & 0.2 & 11 \\
\hline annealed to $1000^{\circ} \mathrm{C}$ & 1.6 & 0.2 & 3 \\
\hline annealed to $1100^{\circ} \mathrm{C}$ & 1.6 & 0.4 & 3 \\
\hline annealed to $1200^{\circ} \mathrm{C}$ & 1.8 & 0.3 & 3 \\
\hline mean annealed value & 1.6 & 0.3 & 9 \\
\hline & & & \\
\hline Fracture on bicrystal grain boundary & & & \\
\hline as milled & 2.9 & 0.3 & 8 \\
\hline annealed to $1000^{\circ} \mathrm{C}$ & 0.7 & - & 1 \\
\hline annealed to $1100^{\circ} \mathrm{C}$ & 1.0 & - & 1 \\
\hline annealed to $1200^{\circ} \mathrm{C}$ & 0.9 & - & 1 \\
\hline mean annealed value & 0.9 & 0.1 & 3 \\
\hline
\end{tabular}


Table 5. Summary of corrected fracture results. All results are corrected for notch/flaw tip bluntness and unannealed specimens are also corrected for the effect of residual stress from ion implantation. SD is the standard deviation of the measurements. \# is the number of measurements. ${ }^{*}$ The $c$ plane fracture surface was facetted i.e. the local fracture was on non-basal crystal planes.

\begin{tabular}{|c|c|c|c|c|c|}
\hline fracture location & specimen & environment & $\begin{array}{l}K_{f(c o r)} \\
\mathrm{MPa} \mathrm{m}^{1 / 2}\end{array}$ & $\begin{array}{l}\text { SD } \\
\mathrm{MPa} \mathrm{m}^{1 / 2}\end{array}$ & $\#$ \\
\hline \multicolumn{6}{|l|}{ crystal fracture } \\
\hline m plane & single crystal & oil & 3.5 & 0.2 & 2 \\
\hline $\mathrm{m}$ plane & single crystal & water & 0.9 & 0.2 & 4 \\
\hline $\mathrm{m}$ plane & single crystal & air & 1.5 & 0.2 & 14 \\
\hline a plane & single crystal & air & 1.4 & 0.2 & 8 \\
\hline c plane* & single crystal & air & 1.5 & 0.2 & 21 \\
\hline within grain & polycrystal & air & 1.6 & 0.2 & 3 \\
\hline \multicolumn{6}{|l|}{ grain boundary fracture } \\
\hline diffusion bonded boundary & bicrystal & air & 0.7 & 0.3 & 16 \\
\hline grain boundary & polycrystal & air & 0.7 & 0.2 & 6 \\
\hline
\end{tabular}



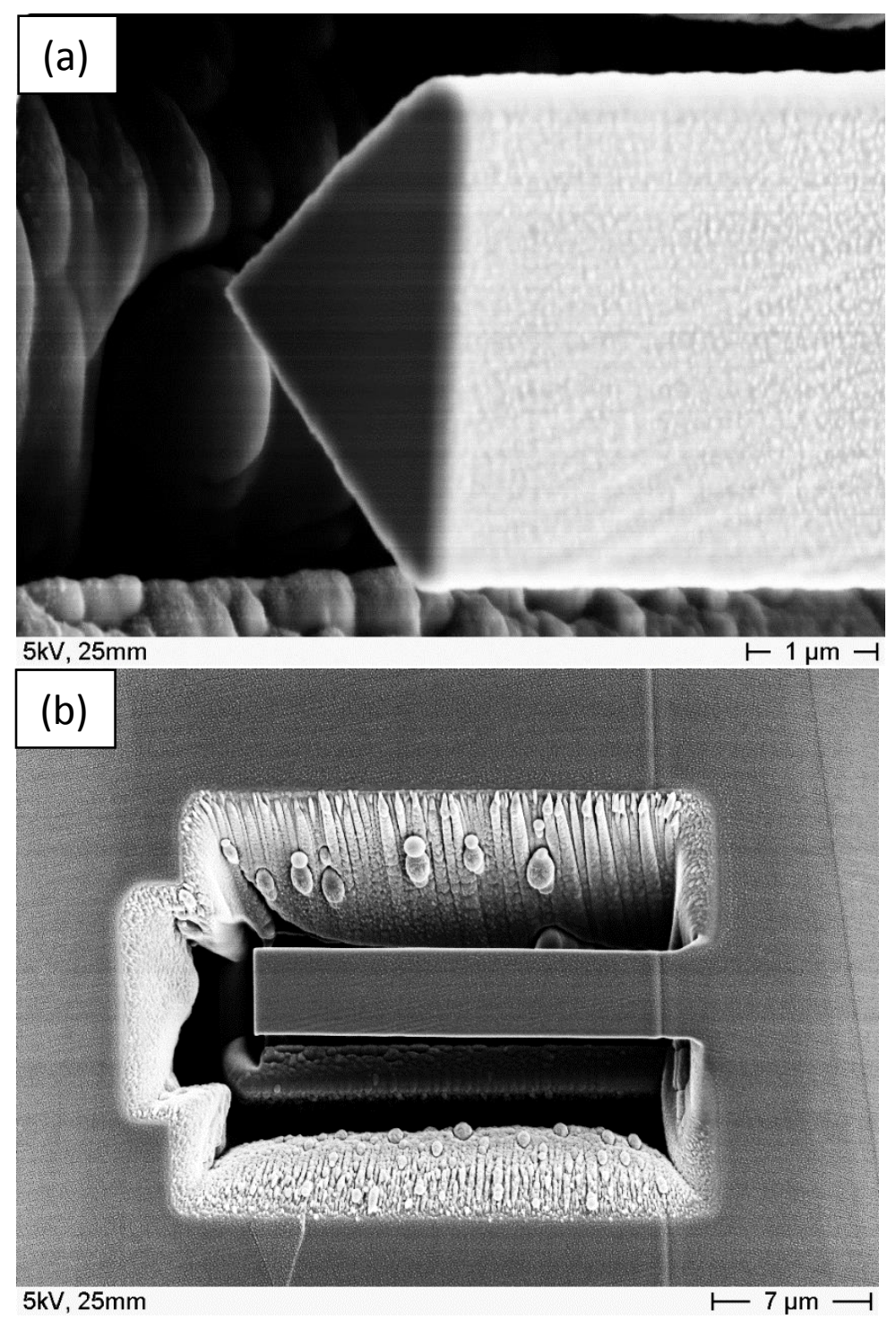

Figure 1. Un-notched microcantilever beam in diffusion bonded sapphire: a) the free end, tilted to $50^{\circ}$, and $b$ ) the beam in its trench before loading. The line crossing the beam near the built-in end is the thermally etched grain boundary. 


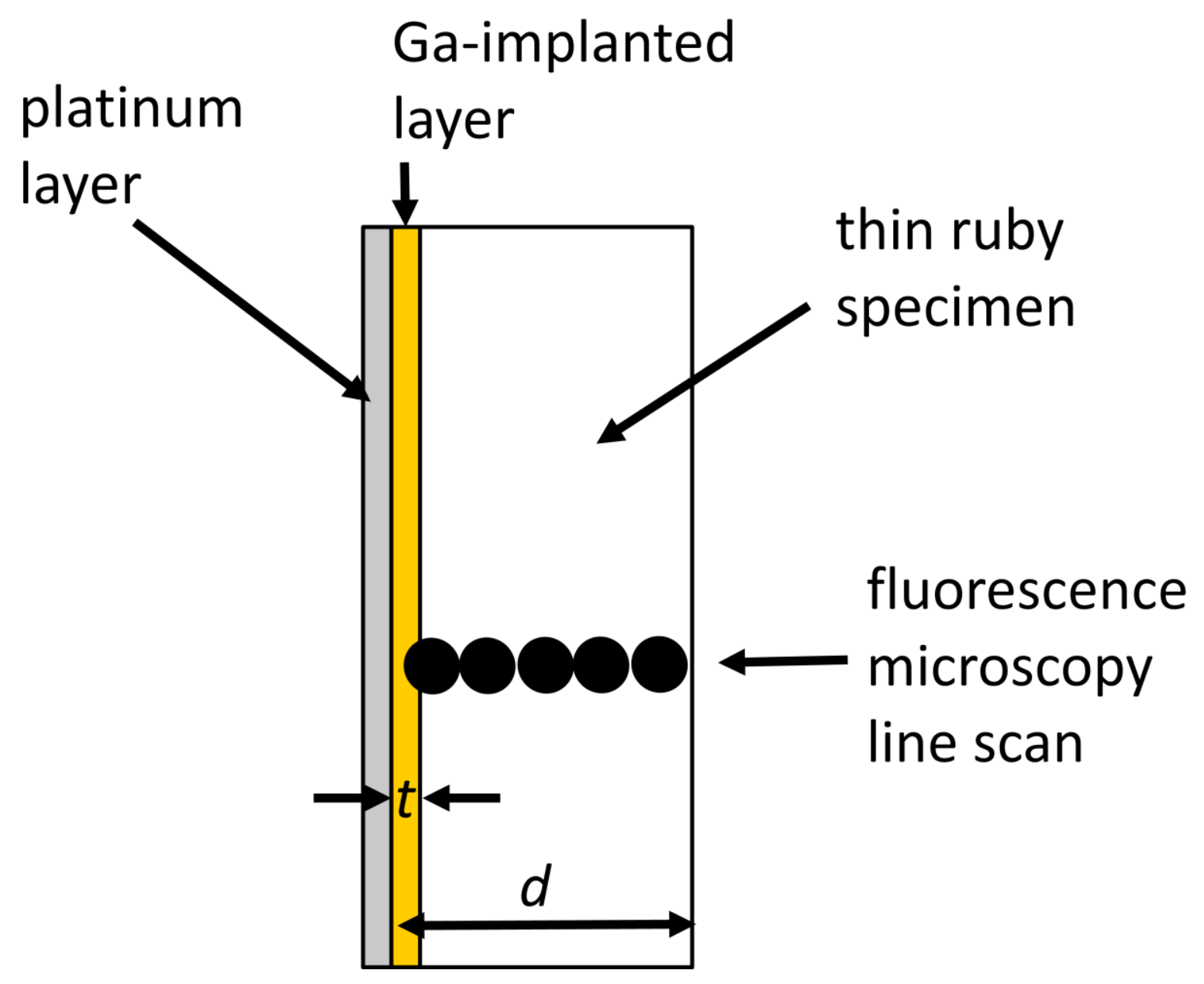

Figure 2. Schematic of curvature experiment for estimating implant stresses (not to scale). 


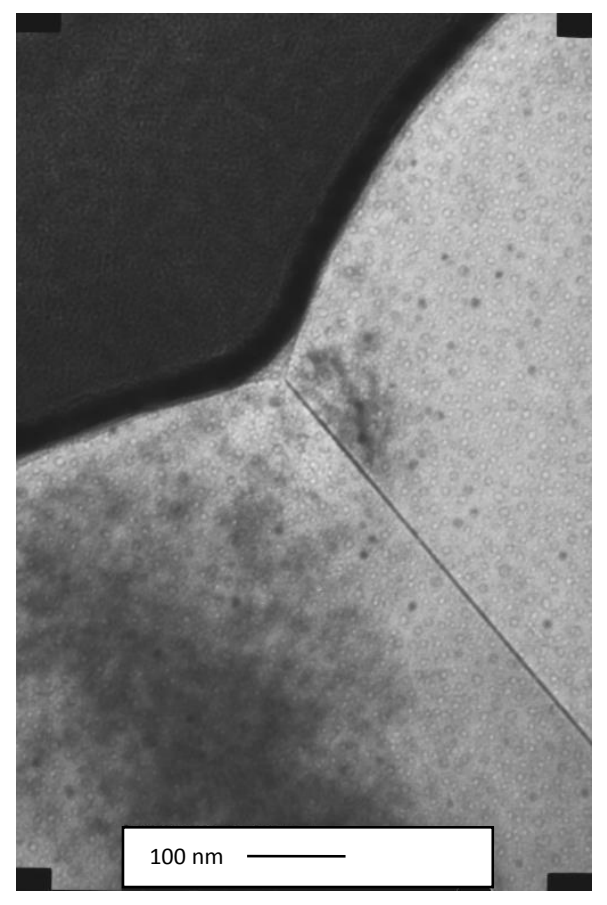

Figure 3. TEM micrograph of DB grain boundary at the surface of the bicrystal. 


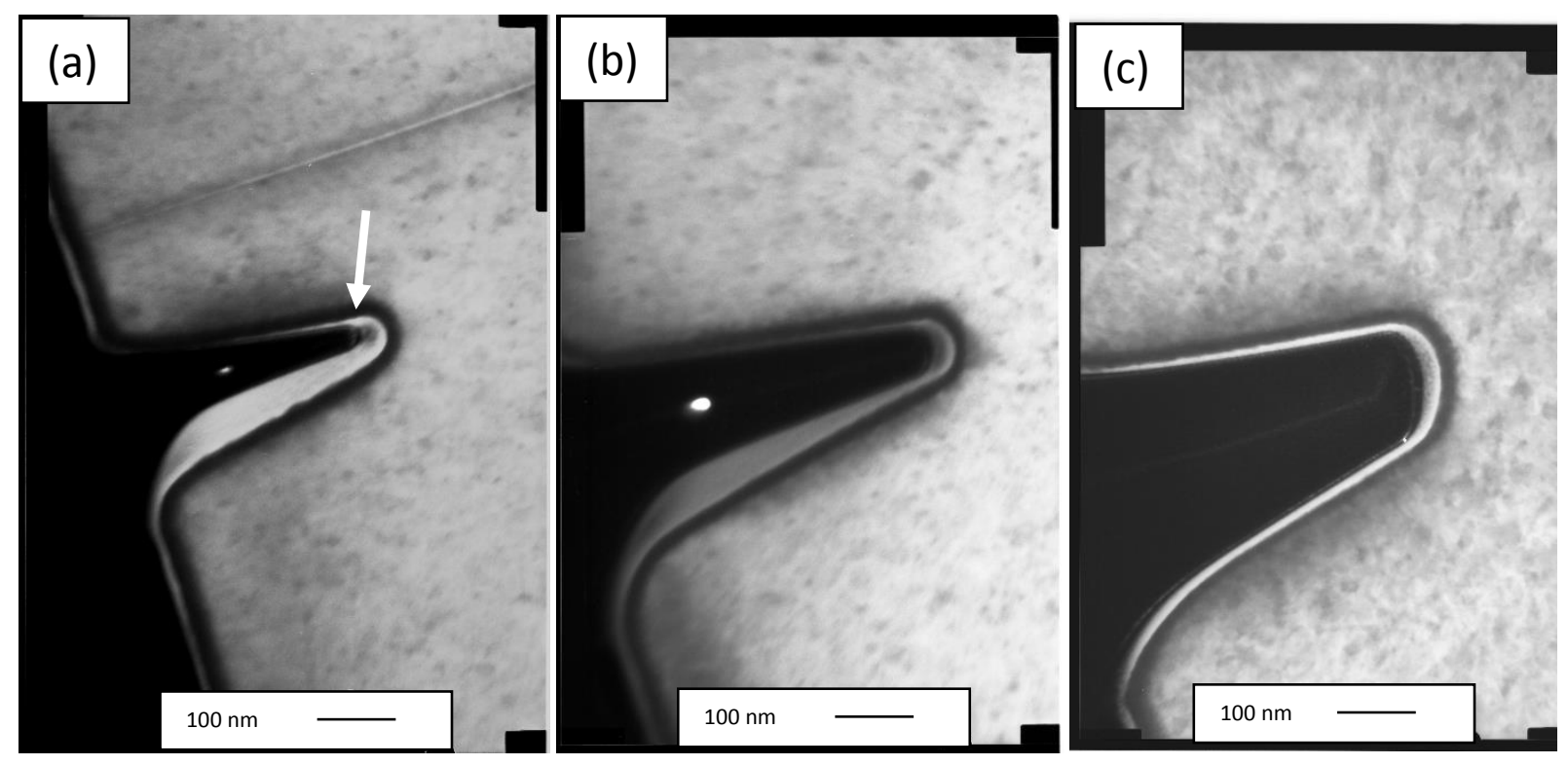

Figure 4. TEM of FIB milled notches, filled with platinum from the specimen preparation, at the surface of sapphire at beam currents of: a) 10pA, b) 100pA, and c) 1000pA. The arrow indicates the Ga ion implanted surface layer in the sapphire. 


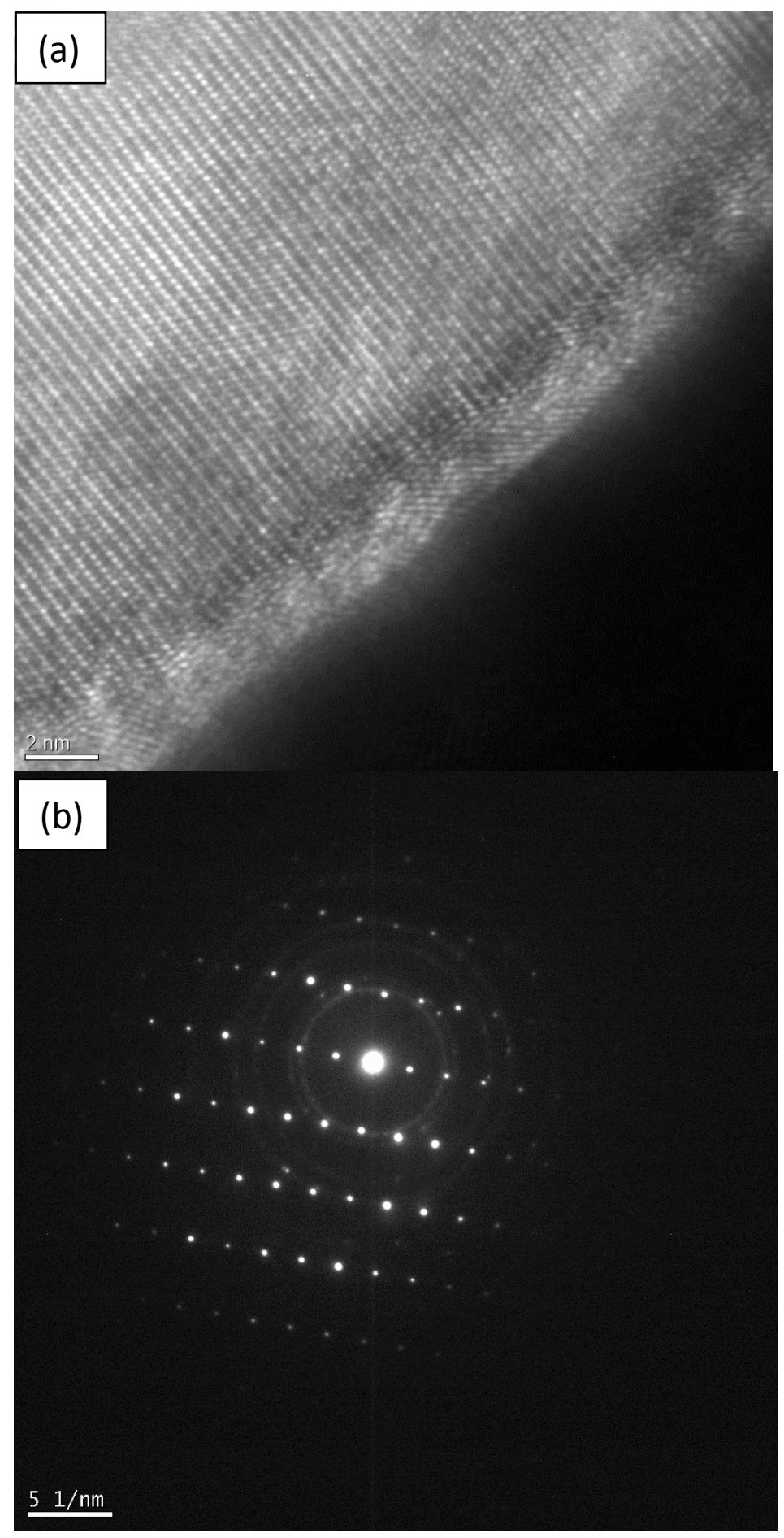

Figure 5. (a) HRTEM of implanted surface showing lattice fringes and thin layer ( $2 \mathrm{~nm}$ ) of redeposited material. (b) $[10 \overline{1} 0]$ nanobeam diffraction pattern from implanted layer. 


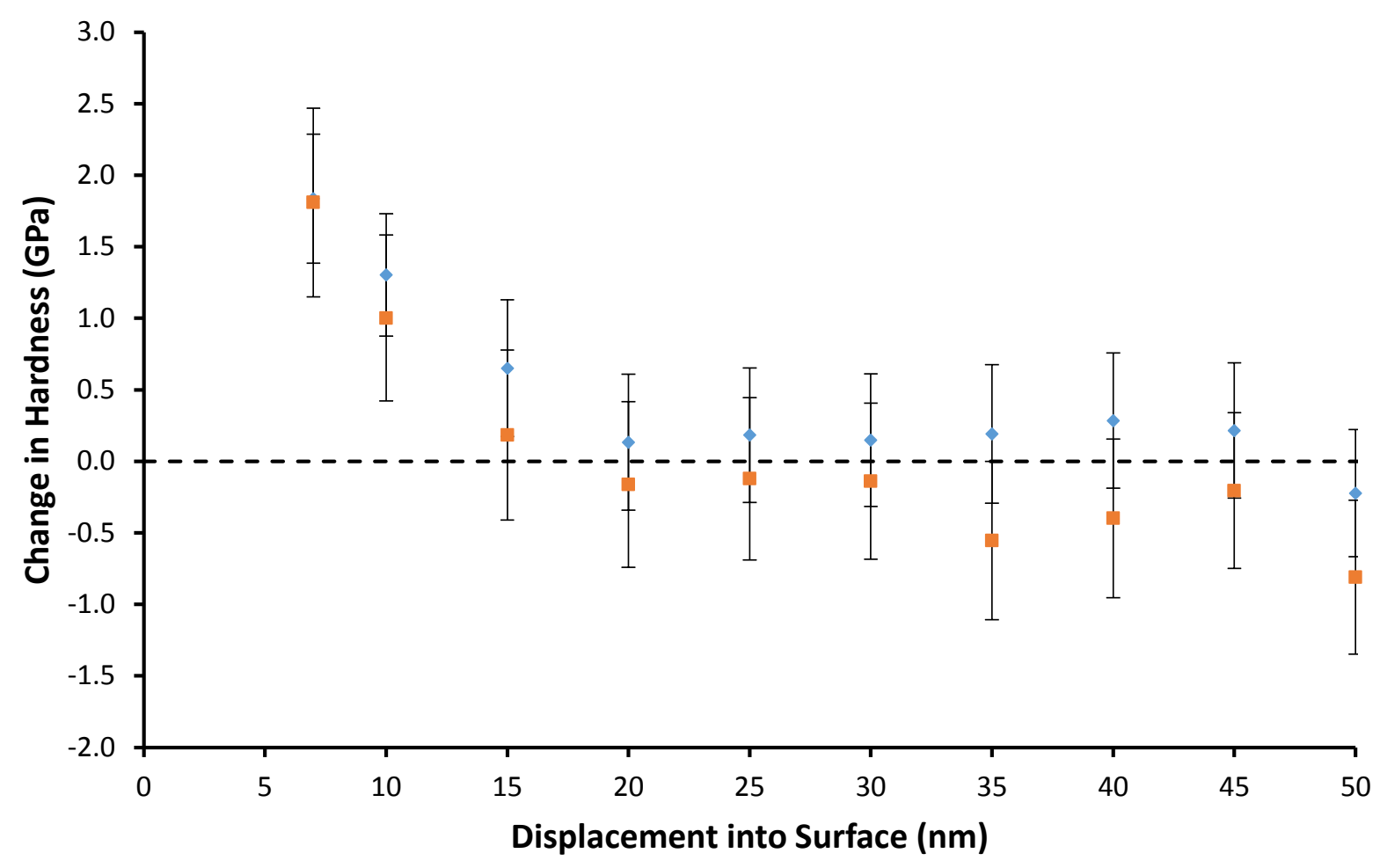

Figure 6. Increase in hardness of c-plane sapphire after imaging in the FIB relative to unimplanted material as a function of indentation depth. Different symbols are from two different regions of the specimen. Each point represents the average value at the relevant depth from 25 indentations. 


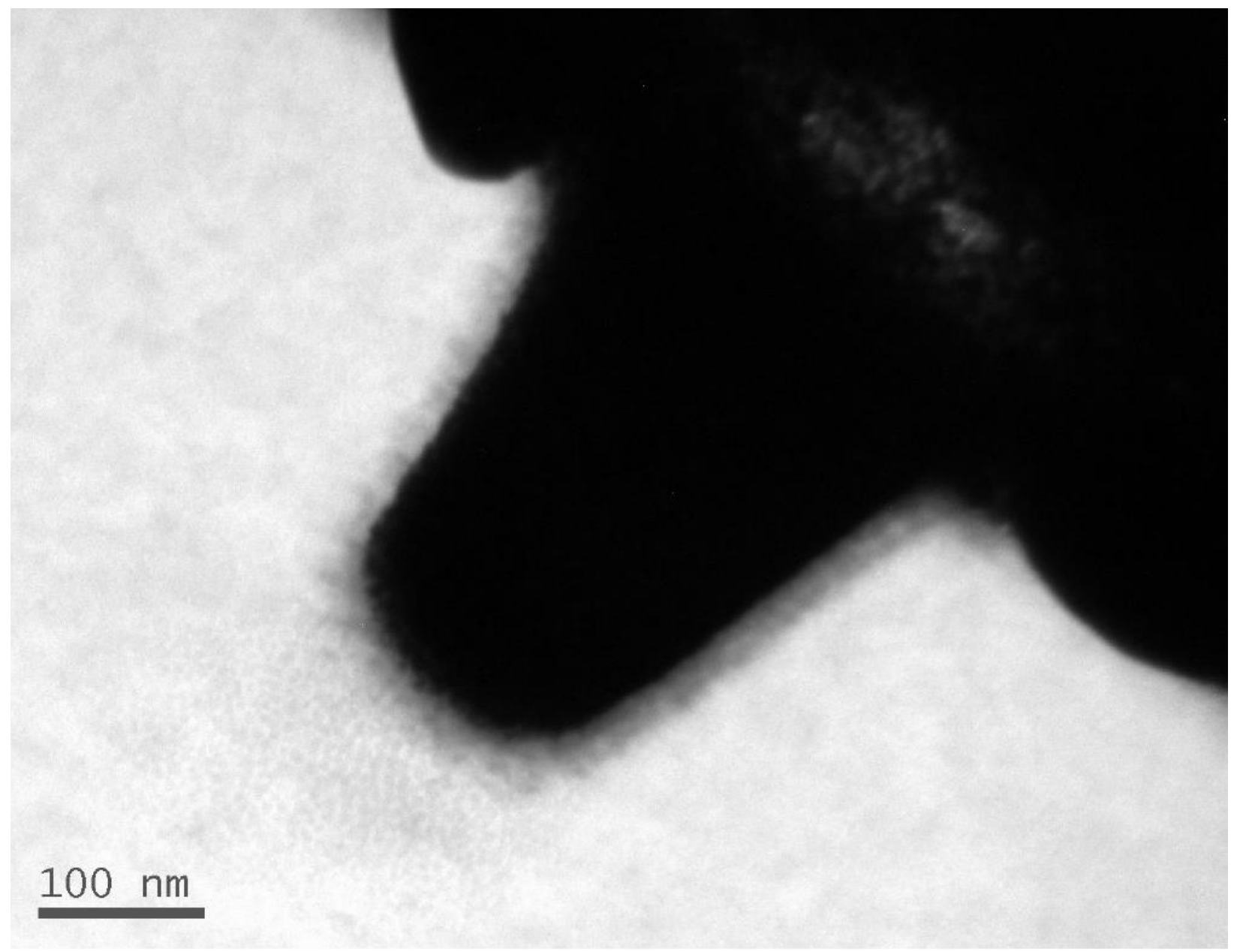

Figure 7. Cross-sectional TEM image of the notch annealed in vacuum. 


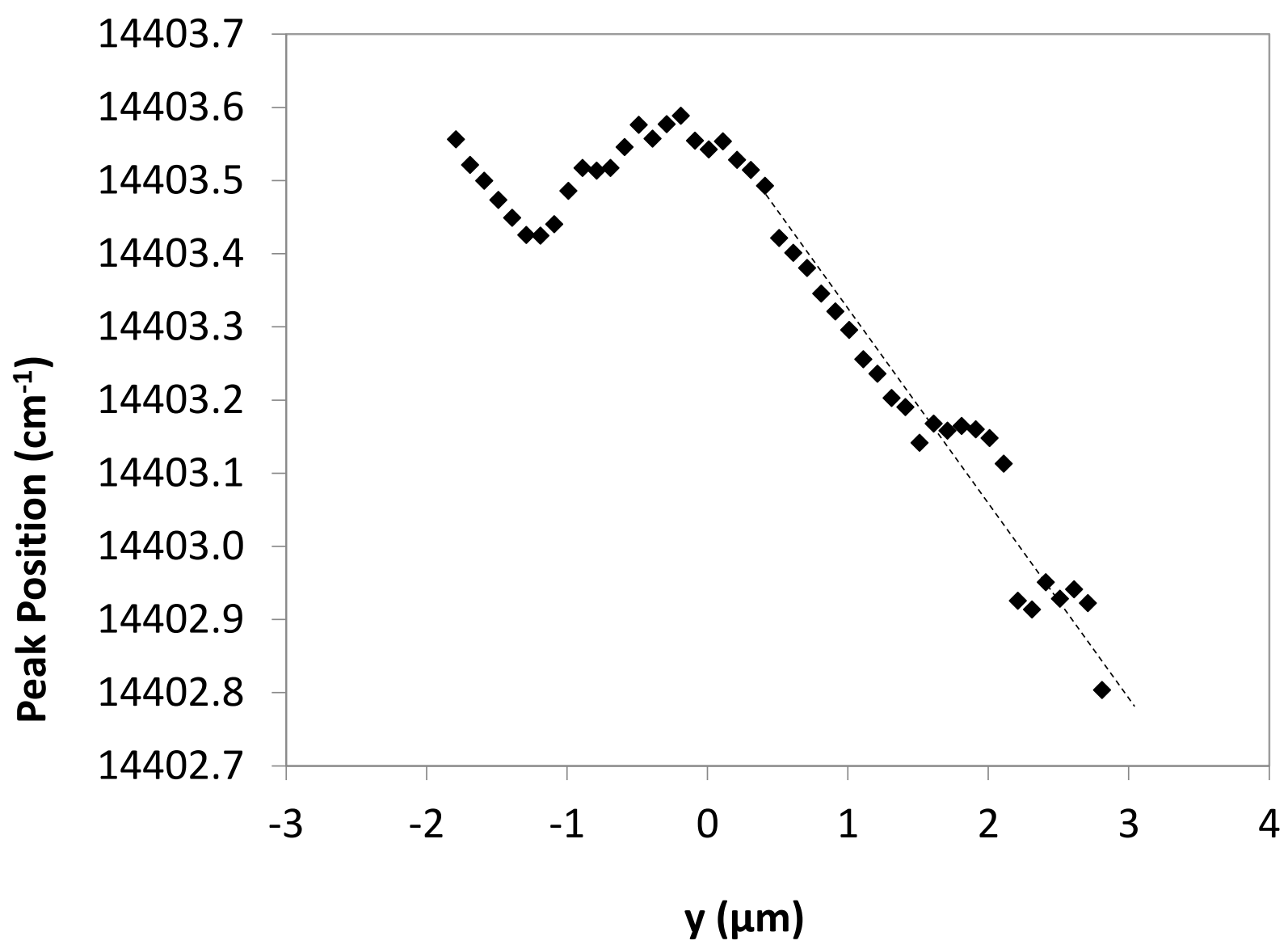

Figure 8. $R 1 \mathrm{Cr}^{3+}$ fluorescence peak position along a line scan normal to the ion implanted edge of the FIB lift out specimen. The implanted edge is at $y=-2 \mu \mathrm{m}$. The gradient of dotted line was used in eq. 4 to calculate the curvature. 

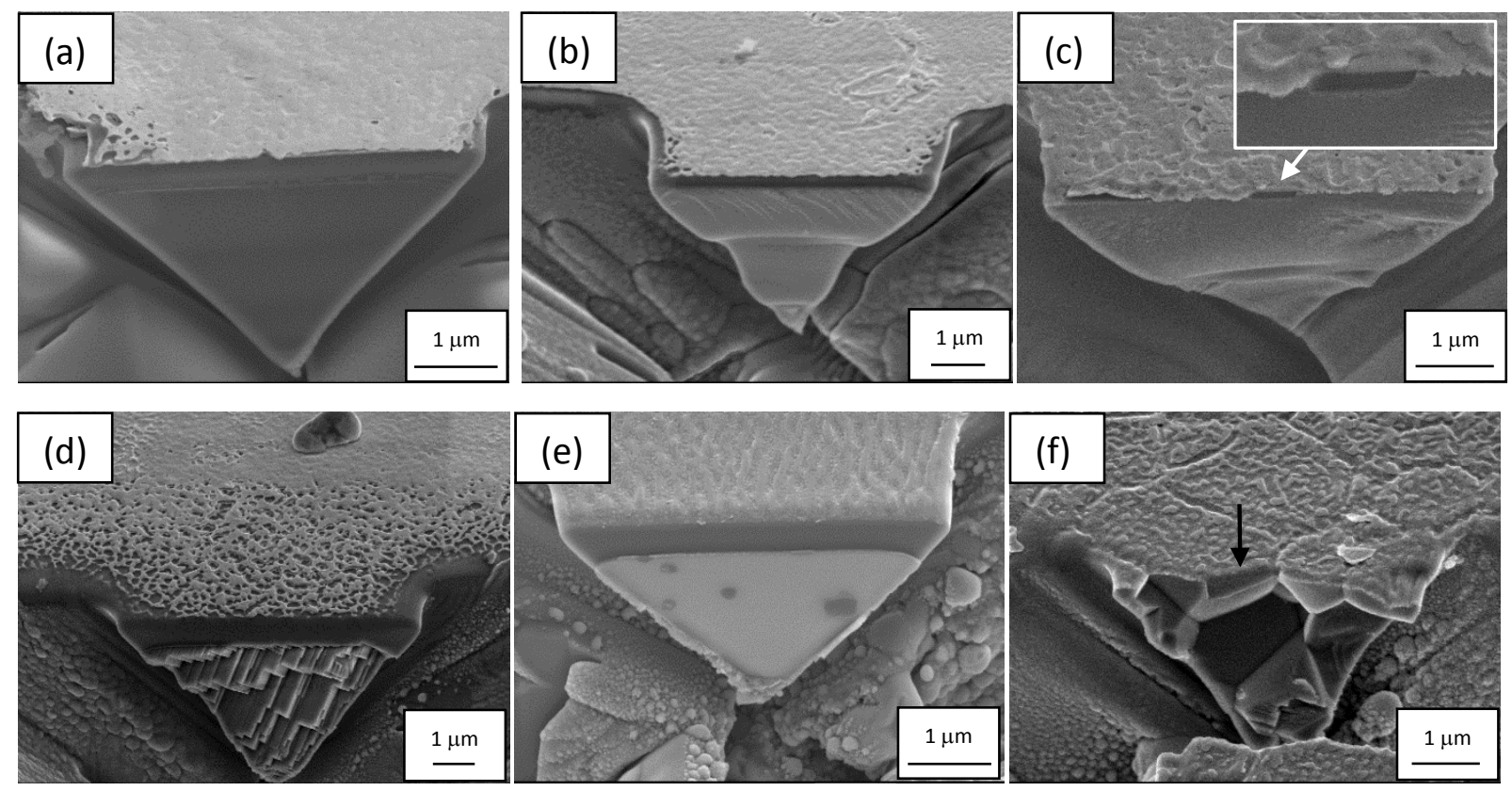

Figure 9. Fracture surfaces of different types of microcantilever beam. (a) Fracture on $m$ plane showing smooth, straight-through fracture. (b) As for (a) but with blunt notch (radius $=76 \mathrm{~nm}$ ) showing hackle and "cantilever curl". (c) Fracture from small FIBed flaw (inset) on a plane. (d) Specimen orientated for fracture on $c$ plane showing heavily facetted fracture surface. (e) Fracture surface from notched DB grain boundary. (f) Fracture from flaw (arrowed) FIBed on grain boundary of polycrystalline alumina showing intergranular fracture in the vicinity of the fracture origin. 


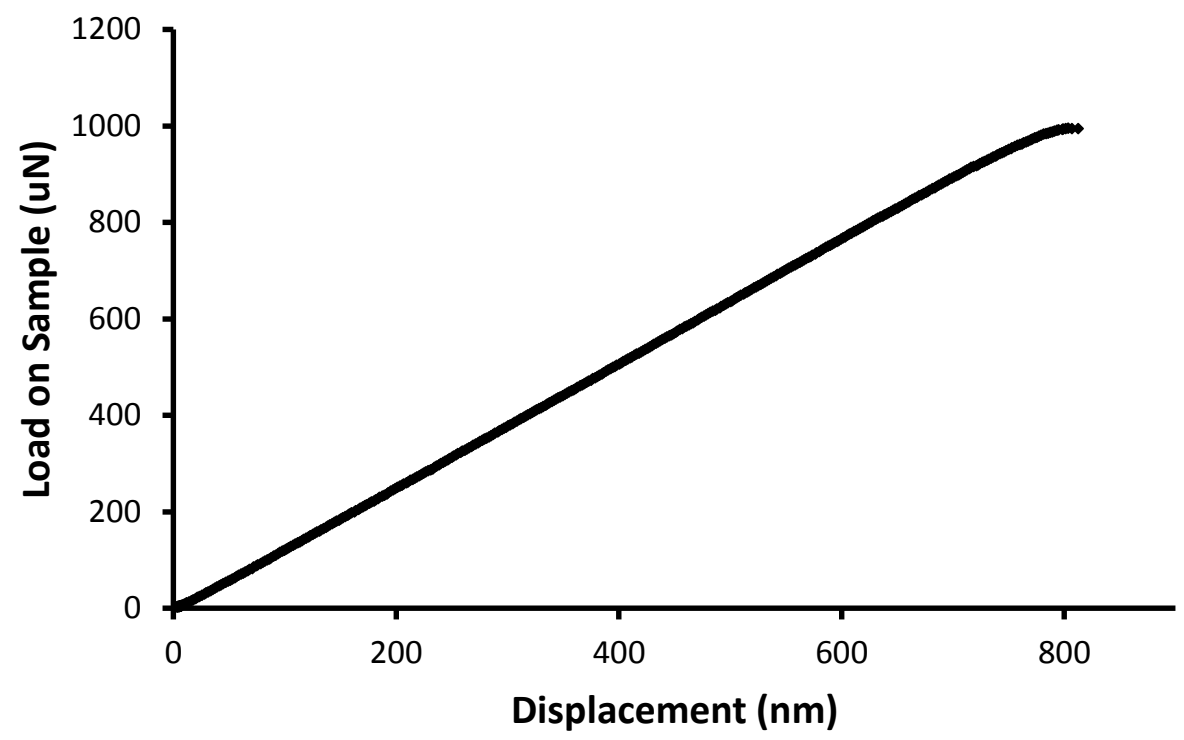

Figure 10. Load displacement curve for a specimen notched on $c$ plane and annealed at $1000{ }^{\circ} \mathrm{C}$ before testing. Note the deviation from linearity before failure. 


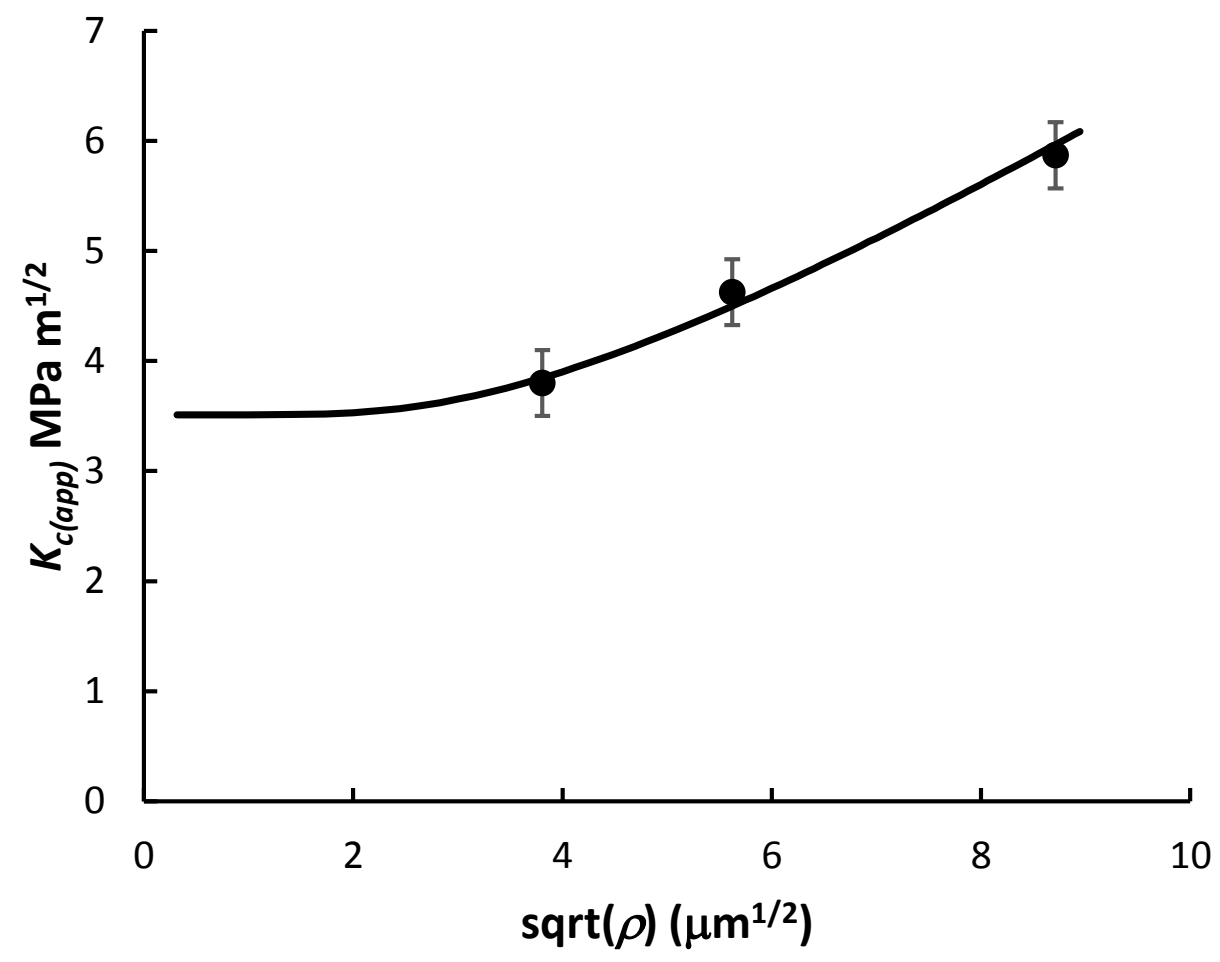

Figure 11. Apparent toughness against square root of notch root radius. Points: experimental. Line: fit to eq. 5. 


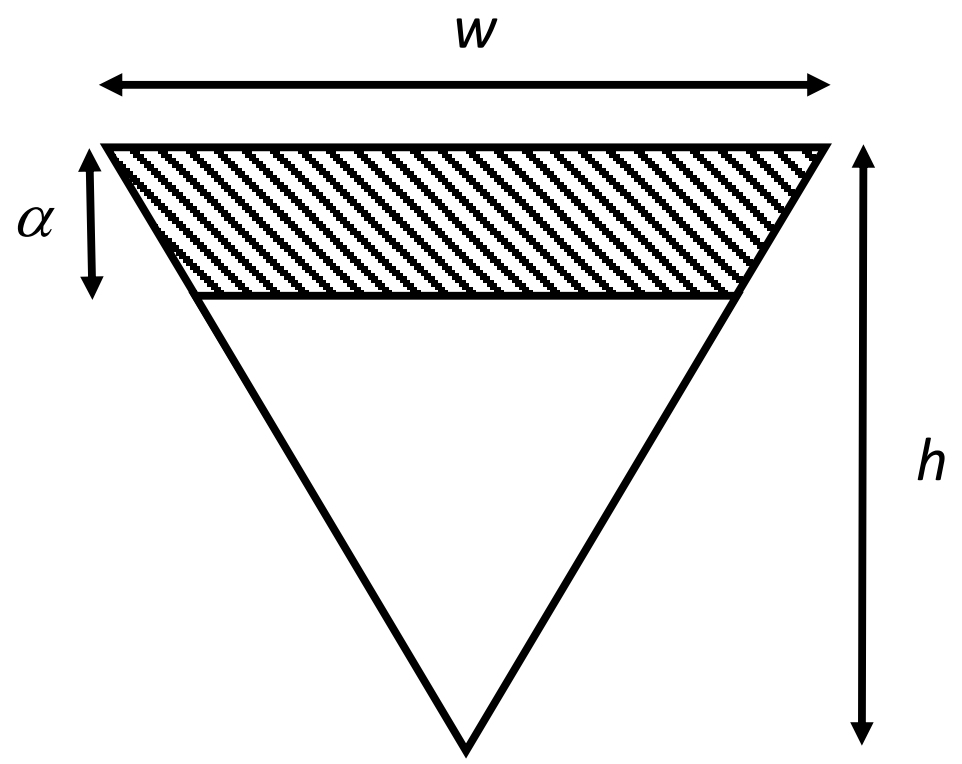

Figure A1. Cross section of edge-notched beam. 